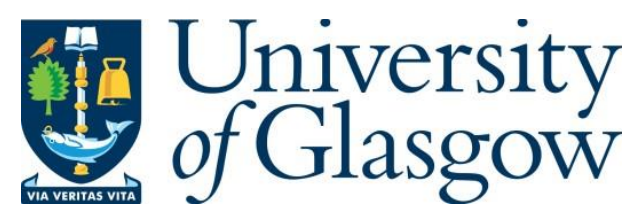

Kirsanova, T., Machado, C. and Ribeiro, A. P. (2018) Should the ECB coordinate EMU fiscal policies? International Journal of Central Banking, 14(3), pp. 237-280.

There may be differences between this version and the published version. You are advised to consult the publisher's version if you wish to cite from it.

http://eprints.gla.ac.uk/152341/

Deposited on: 24 November 2017

Enlighten - Research publications by members of the University of Glasgow

http://eprints.gla.ac.uk 


\title{
Should the ECB coordinate EMU fiscal policies?*
}

\author{
Tatiana Kirsanova ${ }^{\dagger}$ \\ University of Glasgow
}

\author{
Celsa Machado $\ddagger$ \\ ISCAP
}

\author{
Ana Paula Ribeiro ${ }^{\S}$ \\ University of Porto
}

November 3, 2017

\begin{abstract}
In a monetary union where fiscal authorities act strategically fiscal cooperation is unlikely to emerge as an equilibrium. Even when the cooperative outcome is the best for a national fiscal authority, it is either not a Nash equilibrium, or only one of several Nash equilibria. The monetary authority may have an important coordinating role; however, the Pareto-preferred equilibrium will not necessarily involve cooperation.
\end{abstract}

Key Words: Monetary and Fiscal Policy Coordination, Monetary Union JEL Reference Number: E52, E61, E63

\footnotetext{
${ }^{*}$ We are grateful to the editor, Pierpaolo Benigno, our discussant, Paolo Pesenti, and to participants at the 2017 Annual Conference of the International Journal of Central Banking for helpful comments and feedback. We would also like to thank Xiaoshan Chen, Tatiana Damjanovic, Richard Dennis, Campbell Leith, Alexander Matros, Charles Nolan, Christoph Thoenissen, David Vines and Andriy Zapechelnyuk for very helpful comments. All errors remain ours. This research has been financed by the European Regional Development Fund through COMPETE 2020 - Programa Operacional Competitividade e Internacionalização (POCI) and by Portuguese public funds through FCT (Fundação para a Ciência e a Tecnologia) in the framework of the project POCI-01-0145-FEDER-006890

${ }^{\dagger}$ Address: Economics, Adam Smith Business School, Guilbert Scott Building, University of Glasgow, Glasgow G12 8QQ; e-mail tatiana.kirsanova@glasgow.ac.uk

${ }^{\ddagger}$ Address: ISCAP, Rua Jaime Lopes de Amorim, 4465-111 S. Mamede de Infesta, Portugal; email: celsa@iscap.ipp.pt

${ }^{\S}$ Address: Faculdade de Economia da Universidade do Porto, Gabinete nž 608, Rua Dr. Roberto Frias S/N 4200464 Porto, Portugal; email: aribeiro@fep.up.pt
} 


\section{Introduction}

One of aims behind the creation of the EMU has been better policy coordination of the member countries leading to the ultimate synchronization of their business cycles. However, almost two decades of its existence has shown that the degree of policy cooperation between countries is far from desired. There are frequent conflicts of interest, with outcomes leaving member countries unhappy. This is particularly true about fiscal coordination, failures of which are frequently blamed for wide heterogeneity in public debt levels across countries. There are, therefore, calls for greater fiscal unification, or for a fiscal union. ${ }^{1}$

Policy coordination in a monetary union has been a long standing issue in economic research. The literature is vast; it frequently addresses the issue of desirability of coordination and argues that the cooperative outcome is high on the list of Pareto-ranked options available to national and/or union-wide policymakers. ${ }^{2}$

In this paper we investigate whether cooperation is sustainable. We argue that in a monetary union where fiscal policymakers act strategically, fiscal cooperation is unlikely to emerge as an equilibrium. Even when the cooperative outcome is the best for a national fiscal authority, it is either not a Nash equilibrium, or only one of several Nash equilibria. In the latter case the monetary authority may have an important coordinating role; however, the Pareto-preferred equilibrium will not necessarily involve cooperation.

These results arise in a standard two-country DSGE model of a monetary union where policymakers act strategically but unable to precommit. A fiscal policymaker in each country has a choice between pursuing national objectives and adopting union-wide objectives, and between earlier and later dates for setting national fiscal policy. The choice of a date allows either to exploit information about the other country's policy or to provide a clear signal to the market. Once made, these choices are built into institutional arrangements for the future. Fiscal policymakers cooperate if they share objectives, and they act non-cooperatively if their objectives differ. Financial markets can be fully or partially integrated.

More specifically, we demonstrate that the outcome of policy interactions is shock-dependent. Efficient technology shocks lead to the unique Nash equilibrium in which both fiscal policymakers choose to follow their national objectives and to act simultaneously. Although each fiscal poli-

\footnotetext{
${ }^{1}$ See discussion in Bargain et al. (2013).

${ }^{2}$ See e.g. Dixit and Lambertini (2003), Beetsma and Debrun (2004), and Chari and Kehoe (2007) to mention only a few. The equilibrium outcome depends on whether the fiscal authorities and the monetary authority can internalize each other's actions, on the type of policy framework and other factors. See recent survey by Beetsma and Giuliodori (2010) and references therein.
} 
cymaker would individually prefer the cooperative outcome with shared union-wide objectives, they are unable to sustain it, because of the Prisoners' dilemma-type coordination problem.

In contrast, inefficient cost-push shocks lead to either a unique or multiple Nash equilibria. The equilibrium is unique if financial markets are fully integrated, and with imperfect financial integration there are multiple Nash equilibria. The unique equilibrium is characterized by the countries retaining national objectives and the large country having an intra-period advantage over the small country. This equilibrium also exists under incomplete financial markets, and another one is the cooperative equilibrium, however the latter equilibrium it is not the best union-wide outcome under these shocks and is Pareto-dominated by the former.

The difference in equilibrium outcomes is mainly explained by the shock-specific policy tradeoffs and the country-size asymmetry which, in turn, imply a very particular ranking of policy regimes for each fiscal policymaker. Under efficient technology shocks the desire and the ability of an intra-period fiscal leader to influence monetary policy responses results in substantial negative spillovers across the border, opening wider gaps for real variables in the fiscal follower's country. The fiscal leader's gain becomes the fiscal follower's loss. As a result, there is a unique Nash equilibrium in which both fiscal policymakers pursue national objectives and fight for the leadership role, choosing to set their policies at the very beginning of each decision period, and thus losing an intra-period advantage over each other. This equilibrium is robust to country-size asymmetries, and to the degree of financial integration.

In contrast, under inefficient cost push shocks the fiscal leader's ability to manipulate monetary policy to its advantage results in positive spillovers across the border, closing the gaps of real variables for the fiscal follower's country. In the regimes with unilateral fiscal leadership both countries gain relative to the regime of simultaneous fiscal moves. Therefore, there is no fight over the fiscal leadership, and multiple Nash equilibria - with fiscal leadership of either country - arise. The relative ability of each fiscal policymaker to manipulate the monetary authority and the set of equilibria are sensitive to the country-size asymmetries, financial openness and global imbalances. Multiplicity of equilibria, however, remains robust to these factors.

We therefore argue that the pervasive multiplicity of policy equilibria and coordination failures suggest an important coordinating role for a supranational authority. In a monetary union with full and complete information, this role can be naturally taken by the Central Bank, as it has access to the same information as the fiscal authorities and can easily communicate with them. We illustrate how an additional asymmetric policy instrument of a Central Bank might work in our model to improve overall welfare and affect sustainability of policy equilibria. 
This paper provides normative, rather than positive, analysis. It complements the existing analysis of optimal cooperative policy in a monetary union by extending it to some selected cases of strategic interactions, still in the environment with complete and perfect information, certainty-equivalence, and with welfare analysis based on microfounded policy objectives. ${ }^{3}$ Its aim is to present policy coordination tradeoffs that strategic policymakers, which are unable to precommit, face with in a monetary union.

The paper is organized as follows. In the next section we outline the model. Section 3 defines all policy scenarios of interest and Section 4 presents the analysis. Section 5 presents several extensions of the model and Section 6 concludes.

\section{Model Highlights}

We use a workhorse two-country model, based on Benigno and Benigno (2003) but with incomplete financial markets as in Benigno (2009). The modeling of fiscal side follows Woodford (2001) and Leeper and Leith (2016), allowing for variable maturity of government debt.

Specifically, the world economy is populated by a continuum of agents on the interval of $[0 ; 1]$. The population on the segment $[0 ; n)$ belongs to country $\mathrm{H}$ (Home), while the rest of the population on $[n ; 1]$ belongs to country $\mathrm{F}$ (Foreign). Each economy is populated by households and firms. Households' preferences reflect home bias in consumption. Firms are monopolistically competitive, and only use labor to produce differentiated tradable goods. The law of one price holds. Each country has an independent fiscal authority, which finances spending by bonds and distortionary taxes. The government debt is tradable and has geometric maturity structure. Financial markets are incomplete ${ }^{4}$, and the portfolio allocation is determined by transaction costs. All profits received by Home country firms and financial intermediaries are rebated to Home households. Countries are subject to technology and cost-push shocks. We assume that countries form a currency union, so there is only one Central Bank and permanently fixed nominal exchange rate. Full details of underlying microfoundations of the model are given in Appendix A, and only the linearized model is presented here. ${ }^{5}$

\footnotetext{
${ }^{3}$ Ferrero (2009) provides a comprehensive study of the role of distortionary taxes in a monetary union where all policymakers are able to precommit, optimal simple rules for spending are analyzed in Kirsanova et al. (2007).

${ }^{4}$ Baele et al. (2004) argues that in the beginning of 2000s the public debt market was fairly integrated. However, since the Greek government debt restructuring there is a perceived non-zero probability of a sovereign debt default of an individual country.

${ }^{5}$ Here and elsewhere we refer to the Online Appendix.
} 


\subsection{Private Sector Equilibrium}

The household optimization problem for country $\mathrm{H}$ yields consumption Euler equation

$$
\hat{C}_{t}=\mathbb{E}_{t} \hat{C}_{t+1}+\sigma \gamma\left(\hat{\pi}_{F t+1}^{*}-\hat{\pi}_{H t+1}\right)-\sigma\left(\hat{\imath}_{t}-\mathbb{E}_{t} \hat{\pi}_{H t+1}\right),
$$

and the arbitrage condition,

$$
\hat{\imath}_{t}=\mathbb{E}_{t}\left(\hat{R}_{t+1}+\hat{\pi}_{H t+1}\right),
$$

where $\hat{C}_{t}$ denotes consumption, $\hat{S}_{t}$ is the terms of trade (relative price of Foreign producer price in terms of Home producer price), $\hat{\pi}_{H t}$ is Home producer price inflation, $\hat{R}_{t}$ is real return on long-term bonds with geometric maturity structure and $\hat{\imath}_{t}$ is short term nominal interest rate. ${ }^{6}$

The firms' optimization problem yields the standard New Keynesian Phillips curve for the producer price inflation

$$
\hat{\pi}_{H t}=\hat{v}_{t}+\lambda\left(\varsigma \hat{Y}_{t}+\gamma \hat{S}_{t}+\frac{1}{\sigma} \hat{C}_{t}+\frac{\tau^{l}}{\mu} \hat{\tau}_{t}^{l}-(\varsigma+1) \hat{z}_{t}\right)+\beta \mathbb{E}_{t} \hat{\pi}_{H t+1},
$$

where $\hat{Y}_{t}$ is output, $\hat{\tau}_{t}^{l}$ is distortionary labour income tax. Here $\hat{z}_{t}$ and $\hat{v}_{t}$ are $\operatorname{AR}(1)$ Home technology and cost-push shock respectively. Parameter $\sigma$ is inverse of the intertemporal elasticity of substitution, $\varsigma$ is inverse of the Frisch elasticity of labor supply, and $\gamma=(1-n) \alpha$ is the import share, which depends on country size $n$ and the degree of trade openness $\alpha$. Parameter $\mu=\frac{\epsilon}{\epsilon-1}$ is monopolistic markup and is related to the elasticity of substitution between home goods $\epsilon$. Parameter $\beta$ is the household discount factor and the slope of Phillips curve $\lambda=(1-\theta \beta)(1-\theta) / \theta$ is a function of the Calvo (1983) probability of price change $\theta$.

There is also an aggregate resource constraint

$$
\hat{Y}_{t}=\left(\frac{C}{Y} \eta(1-\gamma) \gamma+\frac{C^{*}}{Y^{*}} \frac{Y^{*}}{Y} \eta \gamma^{*}\left(1-\gamma^{*}\right)\right) \hat{S}_{t}+(1-\gamma) \frac{C}{Y} \hat{C}_{t}+\gamma^{*} \frac{C^{*}}{Y} \hat{C}_{t}^{*}+\frac{G}{Y} \hat{G}_{t},
$$

and the government budget constraint

$$
\begin{aligned}
\hat{d}_{H t}+\frac{Y^{*}}{Y} \hat{d}_{H t}^{*}= & 4 \frac{\delta_{H}}{\beta} \hat{R}_{t}+\frac{1}{\beta} \hat{d}_{H t-1}+\frac{1}{\beta} \frac{Y^{*}}{Y} \hat{d}_{H t-1}^{*}+\frac{G}{Y} \hat{G}_{t} \\
& -\frac{\tau^{l}}{\mu}\left(\gamma \hat{S}_{t}+(\varsigma+1)\left(\hat{Y}_{t}-\hat{z}_{t}\right)+\frac{1}{\sigma} \hat{C}_{t}+\left(1+\frac{\tau^{l}}{\mu}\right) \hat{\tau}_{t}^{l}\right) .
\end{aligned}
$$

where $\hat{d}_{H t}$ is normalized real Home debt held by residents, $\hat{d}_{H t}^{*}$ is normalized real Home debt held by non-residents $^{7}, \hat{G}_{t}$ is government spending. Respectively, $\hat{C}_{t}^{*}, \hat{G}_{t}^{*}, \hat{\tau}_{t}^{* l}, \hat{Y}_{t}^{*}$ and $\hat{\pi}_{F t}^{*}$ are Foreign

\footnotetext{
${ }^{6}$ The linearization is around zero-inflation efficient steady state, ensured by suitable assumptions, see Appendix A. Here and below, hatted variables indicate that they have been linearized relative to their steady states, and the steady states are denoted by letters without time subscript.

${ }^{7}$ See Appendix A for the normalization formula.
} 
consumption, government spending, labour income tax, output and producer price inflation. Parameter $\eta$ is the trade elasticity, and the Foreign country import share is $\gamma^{*}=n \alpha$. Parameters $m_{H}$ and $m_{F}$ are maturity of Home- and Foreign-issued bonds, and $\delta_{H}$ and $\delta_{F}$ are annualized market values of debt to output ratios for respective countries.

For the other country the corresponding equations are

$$
\begin{aligned}
& \hat{C}_{t}^{*}= \mathbb{E}_{t} \hat{C}_{t+1}^{*}-\sigma \gamma^{*}\left(\hat{\pi}_{F t+1}^{*}-\hat{\pi}_{H t+1}\right)-\sigma\left(\hat{\imath}_{t}^{*}-\mathbb{E}_{t} \hat{\pi}_{F t+1}^{*}\right), \\
& \hat{\imath}_{t}^{*}= \mathbb{E}_{t}\left(\hat{R}_{t+1}^{*}+\hat{\pi}_{F t+1}^{*}\right), \\
& \hat{\pi}_{F t}^{*}= \hat{v}_{t}^{*}+\lambda\left(\varsigma \hat{Y}_{t}^{*}-\gamma^{*} \hat{S}_{t}+\frac{1}{\sigma} \hat{C}_{t}^{*}+\frac{\tau^{* l}}{\mu} \hat{\tau}_{t}^{* l}-(\varsigma+1) \hat{z}_{t}^{*}\right)+\beta \mathbb{E}_{t} \hat{\pi}_{F t+1}^{*}, \\
& \hat{Y}_{t}^{*}=-\left(\frac{C}{Y} \frac{Y}{Y^{*}} \eta(1-\gamma) \gamma+\frac{C^{*}}{Y^{*}} \eta \gamma^{*}\left(1-\gamma^{*}\right)\right) \hat{S}_{t}+\left(1-\gamma^{*}\right) \frac{C^{*}}{Y^{*}} \hat{C}_{t}^{*}+\gamma \frac{C}{Y^{*}} \hat{C}_{t}+\frac{G^{*}}{Y^{*}} \hat{G}_{t}^{*}, \\
& \frac{Y}{Y^{*}} \hat{d}_{F t}+\hat{d}_{F t}^{*}=4 \frac{\delta_{F}}{\beta} \hat{R}_{t}^{*}+\frac{1}{\beta} \frac{Y}{Y^{*}} \hat{d}_{F t-1}+\frac{1}{\beta} \hat{d}_{F t-1}^{*}+\frac{G^{*}}{Y^{*}} \hat{G}_{t}^{*} \\
& \quad-\frac{\tau^{l *}}{\mu}\left(-\gamma^{*} \hat{S}_{t}+(\varsigma+1)\left(\hat{Y}_{t}^{*}-\hat{z}_{t}^{*}\right)+\frac{1}{\sigma} \hat{C}_{t}^{*}+\left(1+\frac{\tau^{* l}}{\mu}\right) \hat{\tau}_{t}^{* l}\right)
\end{aligned}
$$

where $\hat{d}_{F t}^{*}$ is normalized real Foreign debt held by residents, $\hat{d}_{F t}$ is normalized real Foreign debt held by non-residents. $\hat{z}_{t}^{*}$ and $\hat{v}_{t}^{*}$ are $\operatorname{AR}(1)$ Foreign technology and cost-push shock respectively.

The model is closed by the definition of the terms of trade under fixed exchange rate regime

$$
\hat{S}_{t}=\hat{S}_{t-1}-\hat{\pi}_{H t}+\hat{\pi}_{F t}^{*}
$$

two risk premium equations

$$
\begin{aligned}
\hat{\imath}_{t}^{*} & =\hat{\imath}_{t}+\chi Y^{*}\left(\hat{d}_{F t}+4 \omega \varrho \delta_{F} \frac{Y}{Y^{*}}(1-\gamma) \hat{S}_{t}\right), \\
\hat{\imath}_{t} & =\hat{\imath}_{t}^{*}+\chi^{*}\left(\hat{d}_{H t}^{*}-4 \varrho \delta_{H} \frac{Y}{Y^{*}}\left(1-\gamma^{*}\right) \hat{S}_{t}\right) .
\end{aligned}
$$

and the current account equation

$$
\begin{aligned}
& 0=\left(\gamma C((1-\eta)(1-\gamma)+\gamma)-C^{*} \eta \gamma^{*}\left(1-\gamma^{*}\right)\right) \hat{S}_{t}+\gamma C \hat{C}_{t}-\gamma^{*} C^{*} \hat{C}_{t}^{*} \\
& +Y\left(\hat{d}_{F t}-\frac{1}{\beta} \hat{d}_{F t-1}-4 \omega \varrho \frac{\delta_{F}}{\beta}\left(\hat{R}_{t}^{*}+(1-\beta) \hat{S}_{t}\right)\right)-Y^{*}\left(\hat{d}_{H t}^{*}-\frac{1}{\beta} \hat{d}_{H t-1}^{*}-4 \varrho \frac{\delta_{H}}{\beta} \frac{Y}{Y^{*}} \hat{R}_{t}\right)
\end{aligned}
$$

where $\chi$ and $\chi^{*}$ are Home and Foreign portfolio adjustment cost parameters, $\varrho$ is international exposure and $\omega$ measures external imbalances, their definition is given further in Section 2.3. Equation (11) implies that the terms of trade only changes with inflation and is a state variable, 
equations (12)-(13) imply that in a monetary union with incomplete financial markets, households face different short-term interest rates.

With no loss of generality we assume that the Central Bank controls $\hat{\imath}_{t}$. Each of the two independent fiscal authorities in countries $\mathrm{H}$ and $\mathrm{F}$ controls labor income tax rate and government spending, $\left\{\hat{\tau}_{t}^{l}, \hat{G}_{t}\right\}$ and $\left\{\hat{\tau}_{t}^{* l}, \hat{G}_{t}^{*}\right\}$, respectively.

System (1)-(14) describes private sector equilibrium and determines deviations $\hat{C}_{t}, \hat{Y}_{t}, \hat{\pi}_{H t}$, $\hat{R}_{t}, \hat{d}_{H t}, \hat{d}_{F t}, \hat{C}_{t}^{*}, \hat{Y}_{t}^{*}, \hat{\pi}_{F t}^{*}, \hat{R}_{t}^{*}, \hat{d}_{H t}^{*}, \hat{d}_{F t}^{*}, \hat{\imath}_{t}^{*}$ and $\hat{S}_{t}$, given policy $\hat{\imath}_{t}, \hat{G}_{t}, \hat{G}_{t}^{*}, \hat{\tau}_{t}^{l}, \hat{\tau}_{t}^{l *}$ and exogenous stochastic processes $\hat{z}_{t}, \hat{z}_{t}^{*}, \hat{v}_{t}$ and $\hat{v}_{t}^{*}$.

\subsection{Social Objectives}

The social objective is assumed to be the country-size weighed sum of national intertemporary utility objectives,

$$
W=\mathbb{E}_{0} \sum_{t=0}^{\infty} \beta^{t}\left(n U\left(c_{t}, g_{t}, y_{t}\right)+(1-n) U^{*}\left(c_{t}^{*}, g_{t}^{*}, y_{t}^{*}\right)\right)
$$

where $U\left(c_{t}, g_{t}, y_{t}\right)$ and $U^{*}\left(c_{t}^{*}, g_{t}^{*}, y_{t}^{*}\right)$ are flow national objectives, which depend on per capita private and public consumption and output.

It is straightforward to demonstrate that quadratic approximation (up to third order terms) to the social loss function $-W$ around the efficient deterministic steady state can be written as

$$
-W \approx n \frac{\epsilon}{2 \lambda} y(c \xi)^{-\frac{1}{\sigma}} \mathbb{E}_{0} \sum_{t=0}^{\infty} \beta^{t} V_{t}^{H}+(1-n) \frac{\epsilon}{2 \lambda} y^{*}\left(c^{*} \xi^{*}\right)^{-\frac{1}{\sigma}} \mathbb{E}_{0} \sum_{t=0}^{\infty} \beta^{t} V_{t}^{F}+t i p
$$

where tip denotes 'terms independent of policy'. ${ }^{8}$ Quadratic intra-period terms $V_{t}^{H}$ and $V_{t}^{F}$ are

$$
\begin{aligned}
V_{t}^{H}= & \frac{\lambda}{\epsilon} \frac{1-\sigma}{\sigma} \frac{C}{Y} \hat{C}_{t}^{2}+\frac{\lambda}{\epsilon \sigma} \frac{G}{Y} \hat{G}_{t}^{2}+\frac{\varsigma \lambda}{\epsilon}\left(\hat{Y}_{t}-\frac{1+\varsigma}{\varsigma} \hat{Z}_{t}\right)^{2}+\frac{\lambda}{\epsilon}(1-\gamma) \frac{C}{Y}\left(\hat{C}_{t}+\gamma \eta \hat{S}_{t}\right)^{2} \\
& +\frac{\lambda}{\epsilon} \gamma \frac{C}{Y}\left(\hat{C}_{t}^{*}+\eta\left(1-\gamma^{*}\right) \hat{S}_{t}\right)^{2}+\frac{\lambda}{\epsilon} \frac{C}{Y} \eta(1-\eta) \gamma\left((1-\gamma)^{2}+\left(1-\gamma^{*}\right) \gamma^{*}\right) \hat{S}_{t}^{2}+\hat{\pi}_{H t}^{2}, \\
V_{t}^{F}= & \frac{\lambda}{\epsilon} \frac{C^{*}}{Y^{*}} \frac{1-\sigma}{\sigma} \hat{C}_{t}^{* 2}+\frac{\lambda}{\epsilon \sigma} \frac{G^{*}}{Y^{*}} \hat{G}_{t}^{* 2}+\frac{\varsigma \lambda}{\epsilon}\left(\hat{Y}_{t}^{*}-\frac{1+\varsigma}{\varsigma} \hat{Z}_{t}^{*}\right)^{2}+\frac{\lambda}{\epsilon}\left(1-\gamma^{*}\right) \frac{C^{*}}{Y^{*}}\left(\hat{C}_{t}^{*}-\eta \gamma^{*} \hat{S}_{t}\right)^{2} \\
& +\frac{\lambda}{\epsilon} \gamma^{*} \frac{C^{*}}{Y^{*}}\left(\hat{C}_{t}-\eta(1-\gamma) \hat{S}_{t}\right)^{2}+\frac{\lambda}{\epsilon} \frac{C^{*}}{Y^{*}} \eta(1-\eta) \gamma^{*}\left(\left(1-\gamma^{*}\right)^{2}+\gamma(1-\gamma)\right) \hat{S}_{t}^{2}+\hat{\pi}_{F t}^{* 2} .
\end{aligned}
$$

\footnotetext{
${ }^{8}$ To obtain this expression we employ the device of a steady-state employment subsidy and preference level shocks $\xi$ and $\xi^{*}$ (Benigno, 2009), see Appendix B. This allows us to generate a valid LQ approximation to the underlying policy problem across all the types of policy we consider. In distorted steady state the second order approximation to social welfare would include linear terms which would both prevent us calculating a valid secondorder approximation to welfare using a linearized model and would also introduce an inflation bias to our policy problem. Eliminating the level bias allows us to focus on the stabilization bias.
} 


\subsection{Calibration}

\subsubsection{Steady State Restrictions and Fiscal Side}

The fiscal side of the model is characterized by government spending to output ratios $\Theta_{H}=G_{H} / Y$ and $\Theta_{F}=G_{F} / Y$, labour income taxes $\tau^{l}$ and $\tau^{* l}$, maturity of debt $m_{H}$ and $m_{F}$, annualized steady state debt to output ratios $\delta_{H}=\beta m_{H} \frac{\left(B_{H}+B_{H}^{*}\right)}{4 Y}$ and $\delta_{F}=\beta m_{F} \frac{\left(B_{F}+B_{F}^{*}\right)}{4 Y^{*}}$, the share of Home-issued debt held by non-residents $\varrho=\frac{B_{H}^{*}}{B_{H}+B_{H}^{*}}$, and the share of Home-held Foreign debt to Foreign-held Home debt $\omega=\frac{m_{H} B_{F} S}{m_{F} B_{H}^{*}}$. Here $B_{H}$ are Home-issued bonds held by Home residents, $B_{H}^{*}$ are Homeissued bonds held by Foreign-residents, $B_{F}^{*}$ are Foreign-issued bonds held by Foreign residents, and $B_{F}$ are Foreign-issued bonds held by Home-residents.

In the symmetric-countries model we assume that both countries are of equal size and have zero steady-state government debt held by non-residents, $\varrho=0.0$. The total government debt to output ratio is set to $60 \%$ on annual basis $\left(\delta_{H}=\delta_{F}=0.6\right)$.

In the baseline asymmetric-countries model we calibrate the model to real data, assuming that small country H consists of Portugal, Greece, Ireland, Italy and Spain, also labelled 'the Periphery', and large country F consists of the rest of the EMU, also labelled 'the Core'. The calibration is based on data presented in Appendix C.

The total debt to output ratio for small country $\mathrm{H}$ is calibrated $\delta_{H}=1.10$, which is consistent with employment-weighted average debt level in the Periphery countries. The large Foreign country, has $\delta_{H}=0.6$, consistently with the debt level in the Core. The currently observed domestic debt levels are treated as steady state values, rather than initial conditions partly because the current projections (see IMF Fiscal Monitor data) suggest that this level of government debt is expected to persist for at least a decade, thus making these values to be an (implicit) target of policy authorities, as it is expected that all variables are to return to these (steady state) values in the long run. As a significant proportion of the government debt is held by non-residents, we set the value for the Periphery government debt held by non-residents to $\varrho=0.5$. The IMF survey data reported in Appendix $\mathrm{C}$ suggest that the imbalances in long term debt holdings imply $\omega=0.5$, so that the small Home country is a net debtor.

For both models we calibrate the share of government spending to GDP, $\Theta_{H}=\Theta_{F}=0.20$. The average maturity of government debt is set to 7 years $\left(m_{H}=m_{F}=28\right.$, on quarterly basis). The adjustment cost parameter $\chi=\chi^{*}=0.01$ following Benigno (2009).

The steady state tax level needed to service debt is

$$
\frac{\tau^{l}}{\mu}=\Theta_{H}+4 \frac{(1-\beta)}{\beta} \delta_{H}, \quad \frac{\tau^{* l}}{\mu}=\Theta_{F}+4 \frac{(1-\beta)}{\beta} \delta_{F},
$$


and steady state values of all debt components

$$
\frac{B_{H}}{Y}=4(1-\varrho) \frac{\delta_{H}}{\beta m_{H}}, \quad \frac{B_{H}^{*}}{Y}=4 \varrho \frac{\delta_{H}}{\beta m_{H}}, \quad \frac{B_{F}}{Y^{*}}=4 \omega \varrho \frac{Y}{Y^{*}} \frac{\delta_{F}}{\beta m_{F}}, \quad \frac{B_{F}^{*}}{Y^{*}}=4\left(1-\omega \varrho \frac{Y}{Y^{*}}\right) \frac{\delta_{F}}{\beta m_{F}} .
$$

\subsubsection{Structural Parameters and Shocks}

Calibration of structural parameters is standard. The model frequency is quarterly. The household's discount factor $\beta$ is set to 0.99 which gives the steady state interest rate of $4 \%$. Calvo parameter $\theta$ is set to 0.75 which implies the average length of fixed price contracts of about one year. Openness is set to $\alpha=0.3$. Inverse of the intertemporal elasticity is calibrated $\sigma=0.5$, based on evidence in Attanasio and Weber (1995). Elasticity between home goods $\epsilon=11$ and inverse of the Frisch elasticity of labour supply $\zeta=3$ are calibrated consistently with most estimations of DSGE models (Liu and Mumtaz (2011), Justiniano and Preston (2010), Chen et al. (2017a)). The intertemporal elasticity of substitution between domestic and foreign goods $\eta$ is set to 1.5, see Albonico et al. (2016) and Adolfson et al. (2008).

The relative size of each country is calibrated depending on the nature of the analysis. We use symmetric monetary union consisting of two identical countries with $n=0.5$ when we discuss our main results and the transmission mechanisms. We also study country-size asymmetric monetary union with 'large foreign' and 'small home' countries, where the Home country has size $n=0.3$, as the relative size in terms of population or employment of Greece, Ireland, Italy and Portugal is about one third of the total population of the EMU countries.

The model has four $\mathrm{AR}(1)$ shocks

$$
\begin{array}{rlll}
\text { technology shocks }: & \hat{z}_{t}=\rho_{z} \hat{z}_{t}+\sigma_{z} \nu_{t}, & \hat{z}_{t}^{*}=\rho_{z} \hat{z}_{t}^{*}+\sigma_{z} \nu_{t}^{*}, \quad \nu_{t}, \nu_{t}^{*} \sim \operatorname{iid}(0,1), \\
\text { cost push shocks }: & \hat{v}_{t}=\rho_{v} \hat{v}_{t}+\sigma_{v} \varepsilon_{t}, & \hat{v}_{t}^{*}=\rho_{v} \hat{v}_{t}^{*}+\sigma_{v} \varepsilon_{t}^{*}, \quad \varepsilon_{t}, \varepsilon_{t}^{*} \sim i i d(0,1) .
\end{array}
$$

To calibrate stationary technology shocks we use results from estimation of DSGE models where stochastic trend is removed from the output data, see e.g. Lubik and Schorfheide (2005). This research typically obtains the persistence of an $\mathrm{AR}(1)$ technology shocks $\rho_{z}$ in range [0.3-0.9], see e.g. Chen et al. (2017a), Bianchi (2013) and Lubik and Schorfheide (2005). We calibrate $\rho_{z}=0.85$ and $\sigma_{z}=0.003$. The cost push shock is calibrated to have $\rho_{v}=0.85$ and $\sigma_{v}=0.0025$, consistently with Chen et al. (2017a). ${ }^{9}$ The four shocks are assumed to be independent. All results which we discuss in the paper are robust to calibration of shock parameters.

\footnotetext{
${ }^{9}$ The implied unconditional variance of the shock is much smaller than 0.0217 reported in Smets and Wouters (2003).
} 


\section{Policy Specification}

\subsection{Policy Objectives}

Monetary and fiscal authorities are assumed to set their policies in order to minimize their respective loss functions, given the dynamic structure of the economies.

While the benevolent monetary authority seeks to maximize the union-wide welfare, it is reasonable to assume that national fiscal authorities are exclusively concerned with welfare of their residents and, hence, their objective functions should only include national counterparts. In what follows, therefore, we allocate objectives

$$
\mathbb{E}_{0} \sum_{t=0}^{\infty} \beta^{t} V_{t}^{H} \text { and } \mathbb{E}_{0} \sum_{t=0}^{\infty} \beta^{t} V_{t}^{F}
$$

to Home and Foreign fiscal authorities, respectively, and use the social objective

$$
\mathbb{E}_{0} \sum_{t=0}^{\infty} \beta^{t}\left(n V_{t}^{H}+(1-n) V_{t}^{F}\right)
$$

as a union-wide objective. Here $V_{t}^{H}$ and $V_{t}^{F}$ are the same as used in objective (15). ${ }^{10}$

\subsection{Timing of Moves, Policy Regimes and the Degree of Precommitment}

The timing of main events in this model is conventional: at the beginning of each period the state is realized and observed by all economic agents, the policymakers and the private sector. Knowing the state realization, and anticipating the private sector's reaction - as described by households' and firms' first order conditions - the policymakers choose the level of instruments. Then, at the end of the period, the private sector chooses consumption and prices. ${ }^{11}$ The equilibrium responses of all agents result in a new level of states by the beginning of the next period.

Therefore, policymakers always move after the state is realized and before the private sector takes decisions. There are three policymakers: the Central Bank, and two fiscal authorities. In order to stabilize the economy following shocks they may or may not act in a cooperative way.

Policymakers act cooperatively if they share common objectives. Policymakers act strategically, rather than cooperatively, if their objectives differ. If they do not cooperate, they can make decisions either simultaneously without taking each others' actions into account, or they can anticipate each others' policy decisions, as some of the authorities may have intra-period leadership.

\footnotetext{
${ }^{10}$ We follow e.g. Leith and Wren-Lewis (2011).

${ }^{11}$ This timing is standard in the literature on dynamic monetary policy, see e.g. Clarida et al. (1999).
} 
Taking a stand on intra-period leadership in interactions of monetary and fiscal policymakers deserves some discussion. ${ }^{12}$ In theory, an intra-period leader knows the reaction function of the follower and takes it as a constraint on optimization when choosing its policy. ${ }^{13}$ In practice, does any policymaker have any first move advantage? Conditional on the assumption that monetary and fiscal policymakers optimize, our arguments run along the following lines.

All major central banks proclaim short term stabilization as one of their main aims. The actual conduct of the stabilization policy has always been under investigation by numerous researchers, and there is general consensus that conventional monetary policy reaction function can be reasonably well explained by a Taylor-rule-type linear relationship. It is also well known (e.g. Svensson, 2003) that a Taylor-rule-type linear relationship can be a 'targeting rule', i.e. results from policy optimization. In other words, there is substantial empirical evidence that monetary policy behaves in a systematic way, and we have some reasonably detailed information about its reaction function, and that the reaction function is consistent with optimizing behavior of a central bank. In our framework, this signals in favour of fiscal leadership: a fiscal policymaker has this information and, as a big player, can condition fiscal policy responses on the known monetary policy reaction function.

However, one may argue that fiscal policy is also predictable simply because there are restrictions on its conduct: a limit on borrowing and/or on fiscal deficits. Such restrictions do provide us with information about the fiscal policy reaction function. In the LQ framework, the information about fiscal constraints can most easily be captured by adding appropriate terms into the fiscal policy objective function. For example, an additional term penalizing high fiscal deficits will impose corresponding restrictions on the conduct of fiscal policy. Fiscal policy reaction function, resulting from optimization, will be affected by the form of policy objective. This suggests that monetary leadership would be also possible.

Choosing between these two descriptions of monetary-fiscal policy interactions in an LQ RE framework, we decided not to study the intra-period monetary leadership in this paper. Despite each policymaker's reaction could be predicted by the counterpart to some extent, we believe that this extent, and more precisely the certainty of this extent, is different. First, fiscal policy has not

\footnotetext{
${ }^{12}$ Although it is clearly interesting to study all possibilities, in this paper we restrict our analysis to selected policy scenarios to keep clear focus and avoid too many cases. The discussion of our choice of the leadership structure has been substantially expanded following the Discussant's comments.

${ }^{13}$ See discussion in Beetsma and Giuliodori (2010). It should be stressed that Fiscal Leadership is not the same as Fiscal Dominance and we are not assuming that the central bank is forced to accommodate the actions of the fiscal authority. It is simply that, for example, the fiscal authority may anticipate that the central bank will react to a fiscal stimulus by attempting to stabilize any inflation that it generates.
} 


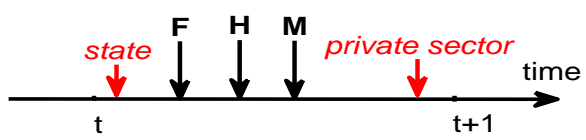

I: Foreign country fiscal authority leads, FHM

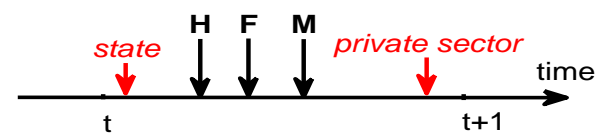

II: Home country fiscal authority leads, HFM

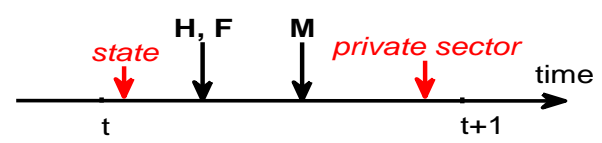

III: Non-cooperative fiscal leadership, [HF]M

Figure 1: Non-cooperative policy regimes and intra-period timing of moves

been systematically used for short term stabilization, certainly not until the Great Recession, and therefore is much less studied by monetary economists. As a result, it is much less predictable by monetary policymakers despite the known constraints on fiscal policy. Moreover, these constraints are frequently violated, so the actual effect of these constraints on fiscal policy reaction function is uncertain. Second, actual fiscal policy operates at much lower frequency than monetary policy, so that the actual monetary policymaker, who needs to make decision now and wants to take into account fiscal policy response, remains uncertain about the exact timing and the extent of the future fiscal response. Actual monetary policy may need to move several times before the response of fiscal policy is certain. These two arguments are based on the uncertainty of timing and of the strength of fiscal policy reactions. Working with an LQ RE model, we rule out the regime of monetary leadership as the one which is less likely to be adequately explained by a model with full and complete information.

Ruling out monetary leadership leaves us with fiscal leadership and with the regime of simultaneous moves, in which neither policymaker takes into account actions of the counterpart. As the base line case in this paper, we concentrate on the regime of fiscal leadership, but we also discuss how our results are amended in case of simultaneous moves. ${ }^{14}$

Having decided to focus on the regime of fiscal leadership, we however remain flexible about the relative intra-period positions of the two fiscal policymakers and consider all possibilities, see Figure 1 which illustrates timing in all regimes which we consider. Moreover, intra-period posi-

\footnotetext{
${ }^{14}$ There is some empirical evidence in favour of fiscal leadership against monetary leadership and the regime of simultaneous moves, although only for the UK and Sweden, which are economies with independent monetary policymakers, see Fragetta and Kirsanova (2010).
} 
tions of the two fiscal policymakers will be determined endogenously, as an equilibrium outcome in policy game. We label fiscal authorities $\mathrm{H}$ and $\mathrm{F}$, and label the monetary authority $\mathrm{M}$.

In what follows, we label three non-cooperative regimes explicitly exploiting the order of moves: FHM, HFM and [HF]M, where in the last regime we use square brackets to indicate that fiscal authorities $\mathrm{H}$ and F make moves simultaneously, see Figure 1.

The cooperative regime is not plotted in Figure 1. The fiscal (and therefore complete) cooperation can be implemented by either giving up national policy instruments to a supranational agent with a union-wide objective, or simply by adopting the union-wide objective instead of national by each fiscal authority. When all agents share objectives then the order of moves is inconsequential. ${ }^{15}$ We label the cooperative regime $\mathrm{C}$.

Finally, we need to take a stand on the degree of policy precommitment. Although there is little doubt that major central banks are able to precommit to an inflation target, the way they actually manage the private sector's expectations of policies to achieve the target remains on research agenda. The early statements of many central banks do not suggest that banks precommit to a plan which is chosen once and forever. Once the Bank of England gained independence, King (1997) proclaimed a regime of 'constrained discretion', accepting discretionary reactions to inevitable 'distractions', but claiming that they will not dominate its policy. Bernanke and Mishkin (1997) gave similar arguments to describe the US monetary policy as discretionary. More recently, some European central banks described their policy as commitment, implemented by means of communicating the 'predictable response pattern', see Bergo (2007) for the view of the Norges Bank and Svensson (2009) for policy recommendations for the Riksbank to follow in the footsteps of Norges Bank by generating optimal policy projections.

Empirical analysis, however, predominantly describes monetary policy as discretionary, see Chen et al. (2017a) for the Europe, Givens (2012), Coroneo et al. (2013) and Chen et al. (2017b) for the US. ${ }^{16}$ Fiscal policy's degree of precommitment is less frequently discussed in the empirical literature; one example is Le Roux and Kirsanova (2013) which demonstrates that non-cooperative discretion dominates non-cooperative commitment in the UK. More recently, Chen et al. (2015) demonstrate that empirical model of the US economy with non-cooperative monetary and fiscal

\footnotetext{
${ }^{15}$ However, in what follows, it is more intuitive to assume that the order of moves under cooperation is the same as under non-cooperation with national policy objectives, such that the only policy change is the adoption of union-wide objective by fiscal authorities without any change in the timing of moves.

${ }^{16}$ Using medium-scale macro models, Bache et al. (2010) for Norges Bank and Adolfson et al. (2011) for Riksbank, find that the past policy of these banks is better explained as optimal policy under commitment than as simple rules, but no comparison with discretion is made. Debortoli and Lakdawala (2016) find only limited degree of precommitment using medium-scale model for the US.
} 
policy operating under discretion dominates the one where fiscal policy operates with rules, while monetary policy operates under discretion. Based on these empirical studies, we assume in this paper that all monetary and fiscal policy decisions are taken under discretion.

\subsection{Solution Algorithm}

Our definition of discretionary policy is conventional and is widely used in the monetary policy literature, see, for example, Backus and Driф 11 (1986), Oudiz and Sachs (1985), Clarida et al. (1999), and Woodford (2003). Solving cooperative case is straightforward, and the numerical algorithm follows Söderlind (1999). The algorithm can be adapted to solve multi-player models, see Currie and Levine (1993) and one implementation in Blake and Kirsanova (2011). For a multi-player game of $k$ participants, the following points are important.

The private sector in a discretionary setup knows that policymakers behave in a time-consistent manner, and sets its aggregate instrument, vector $p_{t}$, which contains inflation, consumption and prices of long-term bonds for our model, as a feedback rule on the vector of states of the economy, $s_{t}$, which are bonds, terms of trade and shocks in our model, and on all policy instruments, $u_{t}=\left[u_{1 t, \ldots}, \ldots u_{k t},\right]$, which are the short term interst rate, government spending and taxes:

$$
p_{t}=\alpha_{s} s_{t}+\alpha_{u} u_{t}
$$

Any policymaker $1 \leq m \leq k$ with instruments $u_{m t}$, who follows one or many other policymakers, treats the vector of leaders' policy instruments $\left(l_{t} \subset u_{t}\right)$ as additional states, and its policy reaction function can be written as a linear rule

$$
u_{m t}=\gamma_{s} s_{t}+\gamma_{l} l_{t}
$$

Therefore, any intra-period leading policymaker with instruments in $l_{t}$ influences decisions $u_{m t}$, of the follower. Any intra-period leader takes this influence into account when formulating its policy. For each policymaker the optimisation problem can be described by a conventional Bellman equation with constraints given by the private sector reaction function in form (16) and by policy reaction functions of all policymaker-followers in form (17). The optimisation results in the system of first order conditions, which is in LQ RE setting is a system of matrix Riccati equations in the unknown coefficients of decision rules $\alpha$-s and $\gamma$-s and in coefficients of value function matrices. A fixed point solution to this system, if exists, satisfies economic agents' expectations and the policy makers' Bellman equations. Solved out value function matrices must be positive semi-deficnite. More details of the solution algorithm are provided in Appendix D. 


\section{Policy Coordination}

This section presents main results on policy coordination in the baseline scenario. It begins by identifying whether policy cooperation is desirable and sustainable in a monetary union with two identical countries. It then explains the economic underpinnings of these results, with inferences about the nature of the policy problem facing by policymakers.

\subsection{Coordination Failures}

Table 1 reports welfare losses for different policy regimes studied in this paper. Each column presents the loss attributed to the corresponding policymaker, $M, H$ and $F$, where subscripts $U$ and $N$ denote the type of objective - union and national - which is used by this policymaker. Here and everywhere else, the loss attributed to a policymaker is computed using its 'true' loss metrics: union-wide loss for $\mathrm{M}$, and national loss for $\mathrm{H}$ and $\mathrm{F}$.

These results suggest, as we further discuss in this section, that cooperation in a symmetric monetary union is unlikely to arise. Cooperation is Pareto-preferred in case of technology shocks, but this equilibrium is not sustainable. The cooperative outcome can emerge if cost push shocks dominate, but it is only one of sustainable equilibria and is not Pareto-preferred in the union as a whole. To facilitate the discussion, we present the results in a reduced-form-game loss matrix in Table 2 .

Assuming that fiscal authorities adhere to their national objectives, outcomes of the policy coordination in a two-by-two game are given in Panel A in Table 2, where each entry reports losses (Home, Foreign). Suppose each fiscal authority has two strategies, to lead (L) or to follow (F), which are loosely interpreted as a strategy to set the Fiscal Policy Committee meeting either before or after the other country's Fiscal Policy Committee has met. The loss matrices in Panel A in Table 2 are filled using entries from columns (1)-(3) in Panels A and B in Table 1. The offdiagonal boxes contain losses of fiscal authorities in regimes FHM and HFM, while the diagonal boxes contain the losses in regime $[\mathrm{HF}] \mathrm{M} .{ }^{17}$

If the economy is subject to technology shocks, then there is a unique Nash equilibrium in which both authorities engage in non-cooperative fiscal leadership $\left(L_{N}, L_{N}\right)$, which corresponds to regime $[\mathrm{HF}] \mathrm{M}$, see Panel A1 in Table 2. ${ }^{18}$ Trying to schedule the Fiscal Policy Committee meeting ahead of the other country, each fiscal policymaker ends up scheduling it in the morning

\footnotetext{
${ }^{17}$ In regime $[\mathrm{HF}] \mathrm{M}$ both fiscal authorities move simultaneously, treating the other player as given. It is straightforward to demonstrate that this is a limiting case of the leadership game.

${ }^{18}$ We limit our analysis to pure strategies.
} 
Table 1: Welfare losses by policymaker and by policy regime, symmetric monetary union Panel A: Policymakers' losses due to technology shocks, $\% \mathrm{C} \times 10^{2}$

\begin{tabular}{|c|c|c|c|c|c|c|c|c|c|c|c|c|}
\hline \multirow[b]{2}{*}{ Regime } & \multicolumn{3}{|c|}{ " National Objectives } & \multicolumn{3}{|c|}{ "Home: Union obj. } & \multicolumn{3}{|c|}{ "Foreign: Union obj. } & \multicolumn{3}{|c|}{ Cooperation } \\
\hline & $M_{U}$ & $H_{N}$ & $F_{N}$ & $M_{U}$ & $H_{U}$ & $F_{N}$ & $M_{U}$ & $H_{N}$ & $F_{U}$ & $M_{U}$ & $H_{U}$ & $F_{U}$ \\
\hline & $(1)$ & $\overline{(2)}$ & $(3)$ & $(4)$ & $(5)$ & $(6)$ & $(7)$ & $(8)$ & (9) & $(10)$ & (11) & $(12)$ \\
\hline FHM & .558 & 569 & 546 & 0.557 & 0.602 & 512 & 0.543 & 0.525 & 0.561 & .538 & 0.538 & 0.538 \\
\hline$[\mathrm{I}$ & FO & 48 & 48 & 543 & 571 & 6 & 13 & 0.516 & 71 & 38 & 38 & 0.538 \\
\hline HFM & 0.558 & 0.546 & 0.569 & 0.543 & 0.561 & 0.525 & 0.557 & 0.512 & 0.602 & 0.538 & 0.538 & 0.538 \\
\hline \multicolumn{13}{|c|}{ Panel B: Policymakers' losses due to cost-push shocks, $\% \mathrm{C} \times 10^{2}$} \\
\hline \multirow{3}{*}{ Regime } & \multicolumn{3}{|c|}{ National Objectives } & \multicolumn{3}{|c|}{ "Home: Union obj. } & \multicolumn{3}{|c|}{ Foreign: Union obj. } & \multicolumn{3}{|c|}{ Cooperation } \\
\hline & $M_{U}$ & $H_{N}$ & $F_{N}$ & $M_{U}$ & $H_{U}$ & $F_{N}$ & $M_{U}$ & $H_{N}$ & $F_{U}$ & $M_{U}$ & $H_{U}$ & $F_{U}$ \\
\hline & $(1)$ & $(2)$ & $(3)$ & $(4)$ & $(5)$ & $(6)$ & $(7)$ & $(8)$ & $(9)$ & $(10)$ & $(11)$ & $(12)$ \\
\hline $\mathrm{M}$ & 0.914 & 935 & .89 & 0.896 & 0.917 & 0.87 & 0.910 & 0.936 & 0.883 & 0.898 & 0.898 & 0.898 \\
\hline$[\mathrm{HF}] \mathrm{M}$ & 0.937 & 0.937 & 0.937 & 0.927 & 0.918 & 0.937 & 0.927 & 0.937 & 0.918 & 0.898 & 0.898 & 0.898 \\
\hline HFM & 0.914 & 0.893 & 0.935 & 0.910 & 0.883 & 0.936 & 0.896 & 0.876 & 0.917 & 0.898 & 0.898 & 0.898 \\
\hline
\end{tabular}

Panel $C$ : Welfare ranking of selected policy regimes

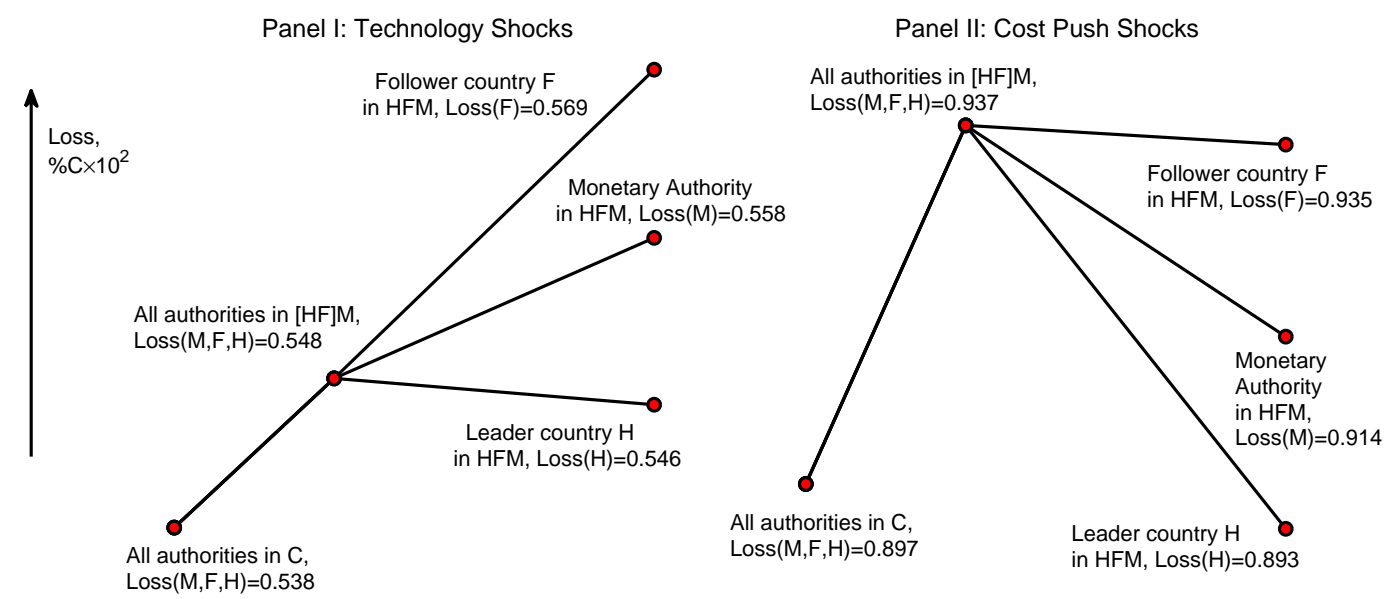

Notes: Here and in all subsequent tables all losses are measured in percentage of steady-state consumption that the consumer would be willing to give up to move from the actual regime to the steady-state allocation.

of the first working day of each fiscal period.

The prevalence of cost-push shocks, however, results in multiple Nash equilibria $\left(F_{N}, L_{N}\right)$ and $\left(L_{N}, F_{N}\right)$, and therefore in coordination failures, see Panel A2 in Table 2. Each country can wait and let the other move first, but if there is an anticipation that the other country will ignore the information available to them about the prospective follower's reaction function when formulating policy, then the better strategy for the country is to move first. 
Table 2: Main results on policy coordination, symmetric monetary union

Panel $A$ : Equilibria in two-by-two game

\begin{tabular}{l|ccc|cc} 
& \multicolumn{2}{c}{ A1: Technology shocks } & \multicolumn{2}{c}{ A2: Cost-push shocks } \\
& & \multicolumn{2}{c}{ Foreign Country } & \multicolumn{2}{c}{ Foreign Country } \\
Home & & $L_{N}$ & $F_{N}$ & $L_{N}$ & $F_{N}$ \\
\cline { 2 - 6 } Country & $L_{N}$ & $\mathbf{( 0 . 5 4 8 , 0 . 5 4 8 )}$ & $(0.546,0.569)$ & $(0.937,0.937)$ & $\mathbf{( 0 . 8 9 3 , 0 . 9 3 5 )}$ \\
& $F_{N}$ & $(0.569,0.546)$ & $(0.548,0.548)$ & $\mathbf{( 0 . 9 3 5 , 0 . 8 9 3 )}$ & $(0.937,0.937)$
\end{tabular}

Panel $B$ : Equilibria in four-by-four game

B1: Technology shocks

Foreign Country

\begin{tabular}{lc|cccc} 
& & $L_{N}$ & $L_{U}$ & $F_{N}$ & $F_{U}$ \\
\cline { 2 - 6 } Home & $L_{N}$ & $(\mathbf{0 . 5 4 8 , 0 . 5 4 8 )}$ & $(0.516,0.571)$ & $(0.546,0.569)$ & $(0.512,0.602)$ \\
Country & $L_{U}$ & $(0.571,0.516)$ & $(0.538,0.538)$ & $(0.561,0.525)$ & $(0.538,0.538)$ \\
& $F_{N} \cdot$ & $(0.569,0.546)$ & $(0.525,0.561)$ & $(0.548,0.548)$ & $(0.516,0.571)$ \\
& $F_{U}$ & $(0.602,0.512)$ & $(0.538,0.538)$ & $(0.571,0.516)$ & $(0.538,0.538)$
\end{tabular}

B2: Cost-push shocks

Foreign Country

\begin{tabular}{lc|cccc} 
& & $L_{N}$ & $L_{U}$ & $F_{N}$ & $F_{U}$ \\
\cline { 2 - 6 } Home & $L_{N}$ & $(0.937,0.937)$ & $(0.937,0.918)$ & $(0.893,0.935)$ & $\mathbf{( 0 . 8 7 6 , 0 . 9 1 7 )}$ \\
\multirow{3}{*}{ Country } & $L_{U}$ & $(0.918,0.937)$ & $\mathbf{( 0 . 8 9 8 , 0 . 8 9 8})$ & $(0.883,0.936)$ & $(0.898,0.898)$ \\
& & & {$[0.898]$} & & \\
& $F_{N}$ & $(0.935,0.893)$ & $(0.936,0.883)$ & $(0.937,0.937)$ & $(0.937,0.918)$ \\
& $F_{U}$ & $(\mathbf{0 . 9 1 7 , 0 . 8 7 6 )}$ & $(0.898,0.898)$ & $(0.918,0.937)$ & $(0.898,0.898)$
\end{tabular}

Notes: Here and in other tables, Losses to (Home, Foreign); losses in Nash equilibria are shown in bold fonts, $\% \mathrm{C} \times 10^{2}$. The number in square brackets is the union-wide loss attributed to the monetary policymaker in a Nash equilibrium.

Table 1 suggests that union-wide welfare loss is lower under cooperation than it is for some of these Nash equilibria. Cooperation requires each policymaker would be willing to either delegate its policy instruments to a supra-national decision maker or, equivalently, adopt the union-wide objectives. Columns (4)-(9) in Table 1 report losses attributed to policymakers in case where either Home of Foreign fiscal authority adopts the union-wide objective unilaterally, while the monetary authority retains the union-wide objective. These losses are then used to construct reduced-form game matrices for the extended four-by-four game, see Panel B in Table 2, where each policymaker is assumed to have four strategies: it can decide to either lead or follow ( $L$ or $F)$ and to either adopt the union-wide objective or adhere to the national objective $(U$ or $N)$. Decisions on leadership and objectives are taken simultaneously, so we use the type of objective as a subscript to the leadership strategy. Once the decision on leadership and policy objective is 
taken, it is built into institutional arrangements. These arrangements determine the stabilization loss attributed to each policymaker. ${ }^{19}$

Panel B1 in Table 2 shows that under technology shocks the unique equilibrium with national objectives $\left(L_{N}, L_{N}\right)$ is robust to the new possibility of adopting union-wide objectives. No fiscal authority will give up national objectives, each of them will continue trying to conduct itself as an intra-period leader, so that the regime of simultaneous fiscal leadership [HF]M will realize.

The multiplicity of Nash equilibria under cost push shocks is also robust to the new set of strategies, see Panel B2 in Table 2. Specifically, there are three Nash equilibria in pure strategies. The are two symmetric equilibria $\left(F_{U}, L_{N}\right)$ and $\left(L_{N}, F_{U}\right)$ in which the leader maximizes the national welfare and anticipates that it will be optimal for the other country to adopt union-wide objectives and follow, without attempting to challenge the first country's leadership position. In the third equilibrium $\left(L_{U}, L_{U}\right)$ each fiscal policymaker adopts union-wide objectives and attempts to lead, ending up scheduling the Fiscal Policy Committee meeting at the first day of each fiscal period. Because objectives are shared, this equilibrium yields the cooperative outcome. If the Home country anticipates that its leadership will be challenged, it will choose to adopt the unionwide objectives, and vice versa.

Out of the three Nash equilibria, the two non-cooperative equilibria $\left(F_{U}, L_{N}\right)$ and $\left(L_{N}, F_{U}\right)$ are the best for the Central Bank, as they deliver the lowest union-wide loss (losses attributed to the monetary policymaker are reported in square brackets in Table 2, Panel B2). Fiscal policymakers can coordinate on any of these three equilibria, not necessarily on the Pareto-preferred.

To summarize, cooperation in the symmetric monetary union under discretionary policy is unlikely to arise. It is Pareto-preferred under technology shocks, but it is not sustainable. The cooperative outcome can emerge under cost push shocks, but it is not preferred by the monetary authority and the union as a whole. Multiplicity of Nash equilibria and coordination failures suggest a possible coordinating role for a supranational authority, which in this environment can be taken by the Central Bank, as it naturally has access to the same information and can communicate easily with the fiscal authorities. ${ }^{20}$

It turns out that the type of equilibrium outcome is robust to changes in model parameterization, and is mostly explained by shock-dependent policy trade-offs, which in turn imply a very particular ranking of policy regimes for each fiscal policymaker. We discuss these trade-offs next.

\footnotetext{
${ }^{19}$ The extended form game includes period zero in which the decision on institutional structure is taken. The subsequent periods are parts of the infinite-horizon monetary-fiscal non-cooperative policy interactions with no precommitment.

${ }^{20}$ See Aumann (1974), Aumann (1987).
} 


\subsection{Transmission Mechanisms}

\subsubsection{Cooperation under technology shocks}

We start with an asymmetric technology shock, positive in country $\mathrm{H}$ but negative in country F, see Figure 2 which only plots impulse responses for country H. We also plot responses in the efficient equilibrium and under international risk sharing. ${ }^{21}$

The transmission mechanism is relatively straightforward, with opposite effects in countries $\mathrm{H}$ and $\mathrm{F}$. Following the shock, the Home producer price falls. In the absence of nominal rigidities the terms of trade $S_{t}=P_{F t} / P_{H t}$ increase efficiently, so as to share the cost of work effort between the two countries, leading to an increase of demand and output in the Home country. The real exchange rate depreciates.

Nominal rigidities preclude that, in face of the shock, the terms of trade increase as much as their efficient level. Consequently, a negative output gap and deflation arise at $\mathrm{H}$ while the opposite happens at F. Income of H-households also increases and, therefore, they consume and save more. However, under incomplete financial markets, H-households are not allowed to lend abroad so much than they would do under international risk sharing. As a result, consumption is closer to its efficient level, but is much higher than under international risk sharing. A larger consumption at $\mathrm{H}$ reduces the marginal utility of consumption and lowers labour supply, exerting an upward pressure on wages and mitigating deflation at $\mathrm{H}$. Thus, incomplete financial markets enable a better stabilization of producer inflation rates, which makes terms of trade to deviate more from their efficient level.

Government spending and taxes increase to stabilize H-inflation (opposite occurs in country F), but this further widens the negative terms of trade gap. As the shock produces smaller effects on inflation under incomplete financial markets than under international risk sharing, policy instruments move by less than under risk sharing but still more than in the efficient equilibrium.

Since net exports increase, country $\mathrm{H}$ becomes net lender, liabilities towards country $\mathrm{F}$ decrease, and holdings of net foreign assets increase. Consequently, under incomplete financial markets, a lower risk premium is levied on H-government debt, decreasing interest rate in country $\mathrm{H}$ (the reverse occurs in country $\mathrm{F}$ ).

Despite yielding slightly better stabilization of inflation, government spending and output, incomplete financial markets increase the terms of trade gap and yield an excessively high relative

\footnotetext{
${ }^{21}$ Although not explicitly discussed in this paper, well-studied international risk sharing provides a convenient benchmark. We use it in Figure 1 only to facilitate the discussion, the specification of the model in this case is given in Appendix A.
} 
consumption. These effects make welfare losses higher than those under risk sharing. ${ }^{22}$

\subsubsection{Non-cooperative regimes and their ranking under technology shocks}

In this model, fiscal policy produces two types of spillovers. Consider again an asymmetric technology shock, positive in country $\mathrm{H}$ and negative in country F. First, fiscal policy produces a negative cross-border effect: increasing taxes and spending in Home country stabilizes H-producer inflation, which accentuates negative terms of trade gap and reinforces positive Foreign output gap; as this pushes further up F-producer inflation, it requires a stronger intervention from F fiscal authority. Second, fiscal policy also produces a positive union-wide externality: increasing taxes and spending in Home country stabilizes H-producer and union-wide average inflation, reducing the need for adjustments from the common monetary policy.

Both above-mentioned spillovers are taken into account when authorities cooperate. However, in the absence of cooperation and pursuing national objectives, national fiscal authorities are unable to internalize the cross-border consequences of their policies and face an incentive to deviate from the cooperative outcome.

Panel I of Figure 3 shows impulse responses under [HF]M and cooperation to an asymmetric technology shock. Similarly, Panel II of Figure 3 shows impulse responses under HFM and [HF]M.

When nationally-oriented fiscal authorities move simultaneously and lead the monetary authority, each of them tries to exploit the first move to take advantage of the union-wide positive externality. Specifically, H-fiscal authority anticipates that if the average union-wide inflation is reduced, then the monetary authority will intervene and reduce interest rate, which helps stabilizing H-producer inflation. Therefore, H-fiscal authority moves both fiscal instruments by less, making them deviate less from their efficient levels than under cooperation.

As plotted in Panel I of Figure 3, relative to cooperative regime $(\mathrm{C}),[\mathrm{HF}] \mathrm{M}$ results in more volatile producer inflation in both countries, but better stabilized terms of trade gap, output, consumption and spending gaps. However, the loss from higher inflation volatility outweighs all other gains, and welfare deteriorates.

When there is a regime with sequential fiscal moves (HFM), the leader, H-fiscal authority, knows that its control for inflation causes a negative cross-border effect, further increasing $\mathrm{F}$ and, consequently, union-wide inflation. $\mathrm{H}$ fiscal authority anticipates that an upward pressure on interest rate, due to the reaction of the monetary authority to an expected increase of the union-wide inflation, will destabilize H-inflation. Thus, to ensure that monetary policy helps

\footnotetext{
${ }^{22}$ Further details are given in Appendix E.
} 

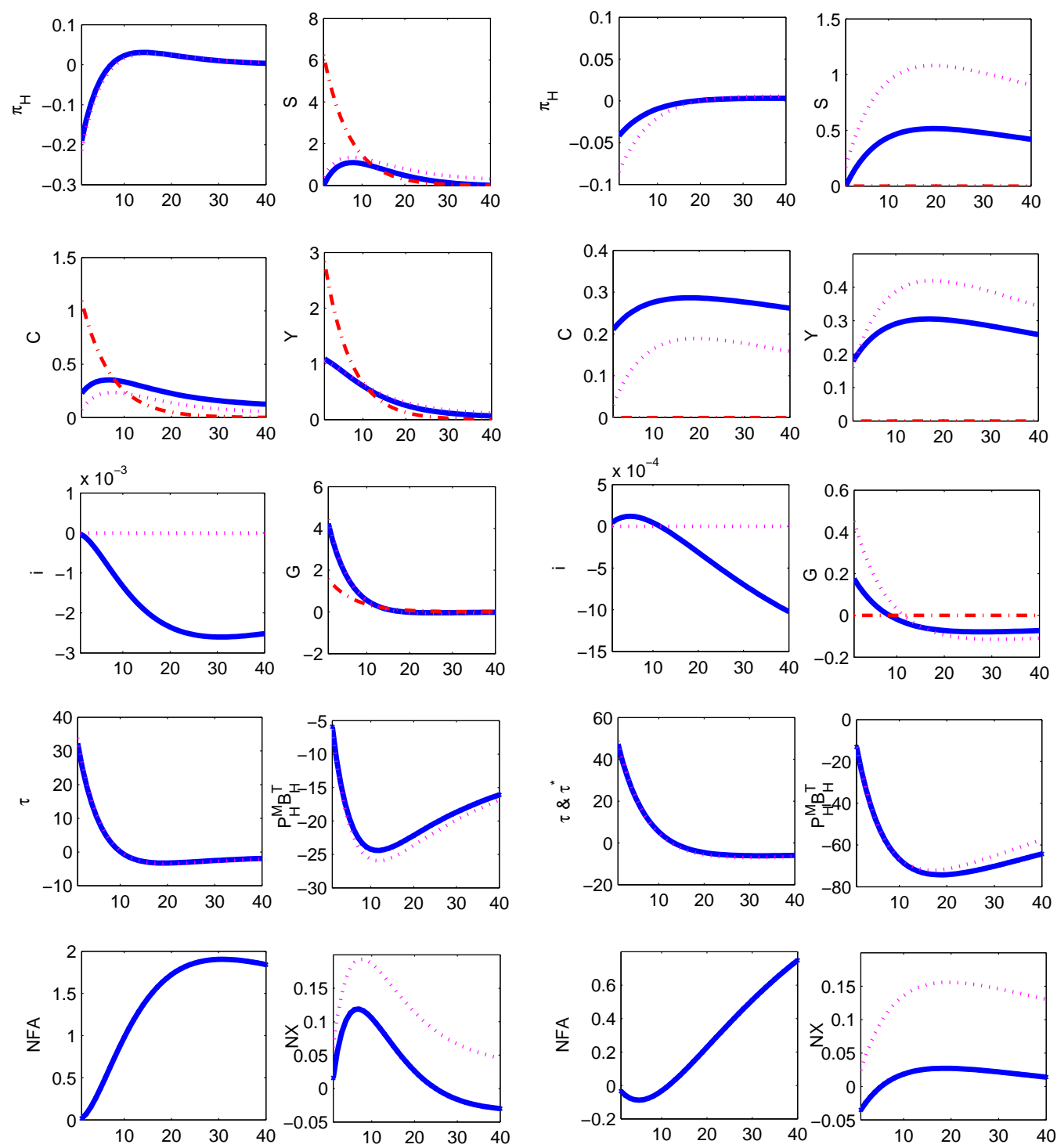

cooperative regime,

incomplete financial markets

- - efficient equilibrium

cooperative regime,

international risk sharing

Figure 2: Transmission mechanism under cooperation (C). Panel I presents impulse responses in country $\mathrm{H}$ to an asymmetric technology shock of size $\frac{1}{\lambda(\varsigma+1)}$, positive in $\mathrm{H}$ but negative in $\mathrm{F}$. Panel II presents impulse responses in country $\mathrm{H}$ to an asymmetric cost push shock of size 1, negative in $\mathrm{H}$ but positive in $\mathrm{F}$. 
stabilizing $\mathrm{H}$-inflation, $\mathrm{H}$ fiscal authority moves its policy instruments even by less, closer to their efficient levels, compared to [HF]M. In this regime fiscal policies are no longer symmetric and the Central Bank lowers interest rate in reaction to a negative average inflation, see Panel II in Figure 3. This monetary policy response increases consumption in both countries and helps to stabilize H-inflation while destabilizes F-inflation. F-fiscal policy has to react in order to undo the harm done by monetary policy.

As plotted in Panel II of Figure 3, regime HFM results in more volatile producer inflation in both countries, but in better stabilized terms of trade gap, relative to regime [HF]M. Consumption, output and the government spending are closer to their efficient levels, and thus are better stabilized at Home, while the reverse occurs in the Foreign country. The gain of better stabilization of real variables outweighs the loss from greater inflation volatility in country $\mathrm{H}$, while the opposite happens in F. Therefore, this regime, compared to [HF]M, allows for higher welfare to the leader country $\mathrm{H}$ (yet lower than under cooperation), and lower welfare in the follower country F. Since the losses in F outweigh the gains in $\mathrm{H}$ due to an excessively volatile $\mathrm{H}$-inflation, the union-wide welfare worsens relative to [HF]M.

Policy equilibrium under technology shock The discussed above relative ranking of noncooperative regimes with fiscal leadership, HFM, FHM and [HF]M produces the unique Nash equilibrium $\left(L_{N}, L_{N}\right)$ in the game where two fiscal policymakers are only allowed to choose the time of their policy decisions, see Table 2, Panel A1.

Despite the cooperative outcome is preferred by each of the policymakers, it is not a Nash equilibrium in the extended four-by-four game, where each fiscal policymaker also decides on whether to adopt the union-wide objective. Consider the leadership regime with simultaneous fiscal moves, but where country F shares the union-wide objective function of the monetary policymaker, while country $\mathrm{H}$ uses the national objective, $\left(L_{N}, L_{U}\right)$. In this scenario, H-policymaker still exploits the first move advantage over the monetary policymaker, raising fiscal instruments by less than it would do under cooperation. Because now country $\mathrm{F}$ and the monetary policymaker share objectives and react on averages, $\mathrm{H}$ and $\mathrm{F}$ policy responses are no longer symmetric and monetary policy ends up helping stabilization of Home country's inflation. Despite cooperation is a better outcome for $\mathrm{F}$, it delivers worse stabilization for $\mathrm{H}$ and, therefore, $\mathrm{H}$ fiscal authority faces incentives to deviate from cooperation by unilaterally adopting national objectives. Very similar dynamics can be observed under either HFM or FHM where, either leading or following, country $\mathrm{H}$ exploits the monetary policy reaction function and has incentives to adopt the national 
Panel I: Cooperative regime vs. Regime of simultaneous fiscal moves
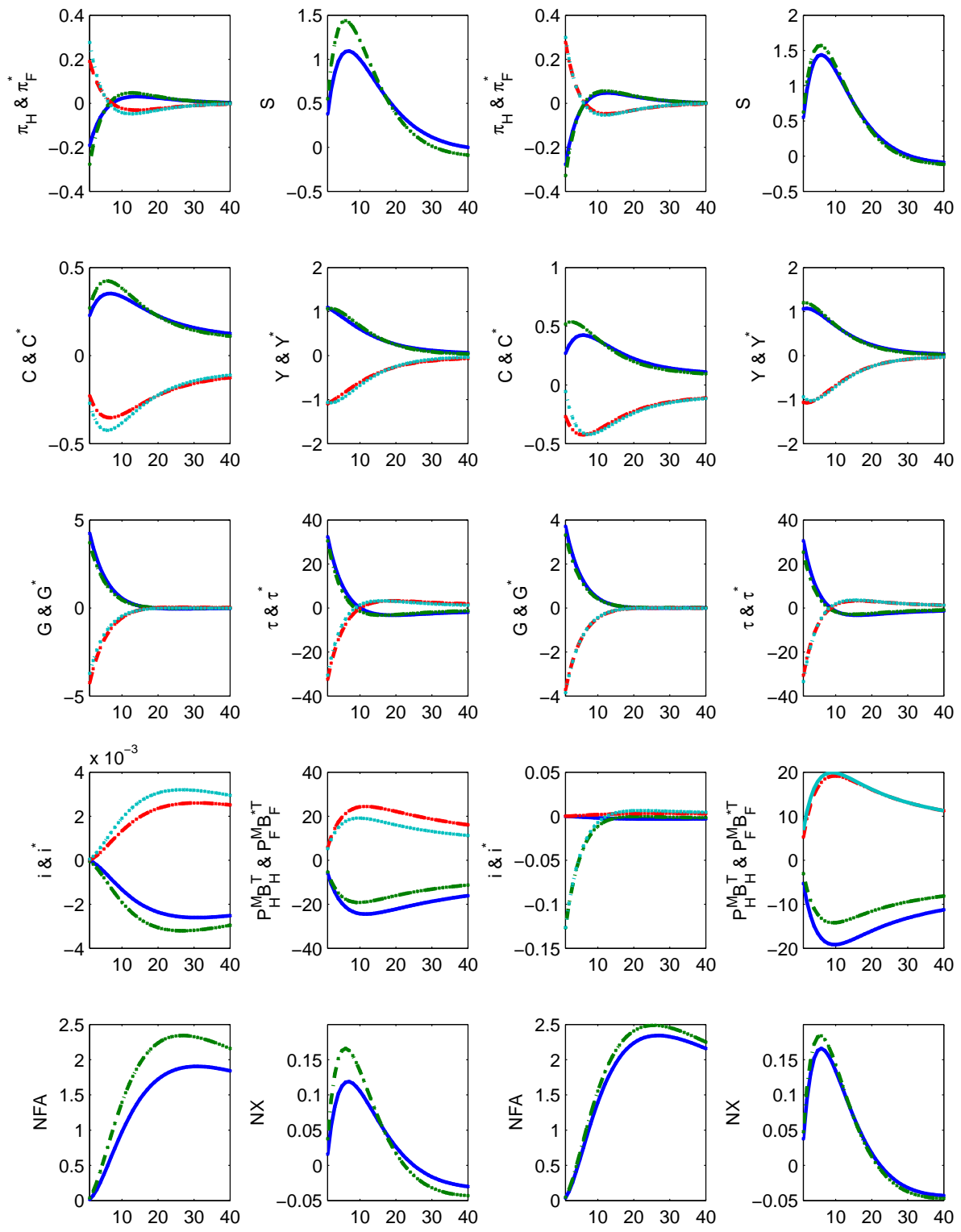

$\longrightarrow \mathrm{H}_{\mathrm{C}}, \ldots, \mathrm{H}_{[\mathrm{HF}] \mathrm{M}}---\mathrm{F}_{\mathrm{C}} \ldots \ldots, \mathrm{F}_{[\mathrm{HF}] \mathrm{M}}$

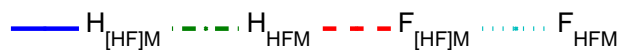

Figure 3: Impulse responses to an asymmetric technology shock of size $\frac{1}{\lambda(\varsigma+1)}$, positive in country $\mathrm{H}$ and negative in country F. Countries are identical, with $\varrho=0$ and $\omega=1$. 
objectives unilaterally.

This incentive of a fiscal policymaker to deviate from cooperative outcome $\left(L_{U}, L_{U}\right)$ prevents it to become a Nash equilibrium in the four-by-four game, see Panel B1 in Table 2. Fiscal authorities have Prisoner's dilemma: despite the joint adoption of the union-wide objectives is better than any non-cooperative outcome under national objectives, the unilateral deviation from union-wide objectives delivers even greater gain to the deviating policymaker. Cooperation, therefore, does not realize under technology shocks, and the non-cooperative fiscal leadership under national objectives [HF]M remains the unique Nash equilibrium.

\subsubsection{Cost-push shocks and fiscal stabilization}

An asymmetric cost push shock, negative in country $\mathrm{H}$ but positive in country $\mathrm{F}$, reduces marginal costs and Home inflation and increases the terms of trade which, by shifting demand from $\mathrm{F}$ to $\mathrm{H}$, contributes to inflation stabilization both at home and abroad. Since cost push shocks have no effect on the efficient flexible-price equilibrium, a positive output gap (and deflation) arises at Home, see Panel II of Figure 2. ${ }^{23}$

Income increases at Home and so does consumption and savings, since domestic and foreign goods are substitutes in utility. However, under incomplete financial markets, H-households are not allowed to lend abroad so much than they would do under international risk sharing. As a result, consumption increases by much more than under international risk sharing. As in the case of technology shocks, a larger consumption at $\mathrm{H}$ reduces the marginal utility of consumption and exerts an upward pressure on wages, mitigating deflation at $\mathrm{H}$. Thus, incomplete financial markets enable a better stabilization of producer inflation rates and also of the terms of trade.

Using taxes it is possible to completely offset the effect of these shocks on inflation, but there are consequences for debt accumulation in this model. Government spending complements the stabilization role of taxes by stabilizing both inflation and debt. As a result, taxes move less than required to offset the shock, keeping part of 'surprise inflation' as it helps to inflate the real debt (see Leeper and Leith, 2016), and government spending in country $\mathrm{H}$ also increases. As the shock produces smaller effects on inflation under incomplete financial markets, fiscal policy instruments adjust by less than under international risk sharing. This is particularly evident for government spending, which volatility causes larger welfare losses.

Due to the inefficiently high consumption and the better stabilization of terms of trade under

\footnotetext{
${ }^{23}$ We can think of efficient tax rates as the ones that eliminate the costs imposed by fluctuations in firms' desired mark-up, Leith and Wren-Lewis (2011).
} 
incomplete financial markets, net exports decrease at $\mathrm{H}$ during the first periods. However, once the terms of trade become high enough, a current account surplus emerges, due to a weaker demand of F-goods in $\mathrm{H}$. Initially, country $\mathrm{H}$ is net debtor and increases its liabilities towards F, while decreases its holdings in foreign assets (NFA fall); the opposite (NFA increase) occurs afterwards. During the initial periods, under incomplete financial markets, a higher risk premium is thus levied on $\mathrm{H}$-government debt, increasing interest rate at $\mathrm{H}$; the reverse occurs subsequently.

In spite of causing higher volatility of consumption and an inefficiently high relative consumption, incomplete financial markets promote a better stabilization of inflation, terms of trade, output and government spending. As the gains in welfare from the latter outweigh the costs of the former, welfare losses are lower than those under international risk sharing. ${ }^{24}$

Under non-cooperation, fiscal authorities fail to internalize cross-border and union-wide spillovers. When both fiscal authorities move simultaneously and lead the monetary authority, they try to exploit the first move advantage by moderating its overall fiscal policy reaction, relying on the stabilization effort of monetary policy. While taxes react slightly more, government spending is strongly moderated, with both becoming closer to their efficient levels. As policy authorities act symmetrically, monetary policy ends up being neutral. Relative to cooperation, terms of trade are more volatile, inflation is slightly more volatile, while consumption, output and government spending become more stable, see Panel I in Figure 4 which plots impulse responses in regime $[\mathrm{HF}] \mathrm{M}$ and under cooperation $(\mathrm{C})$. The welfare losses from larger inflation and terms of trade volatility outweigh the gains from better stabilization of the other variables and overall welfare deteriorates relative to the cooperative regime. ${ }^{25}$

Panel II of Figure 4, compares the impulse responses under the regime with unilateral leadership of country H, HFM, with those under the regime of simultaneous non-cooperative fiscal leadership, [HF]M.

The leader, H-fiscal authority, can substantially improve its welfare relative to the one in regime $[\mathrm{HF}] \mathrm{M}$, similarly to what is achieved under technology shocks. Since H anticipates that its policy reaction will have a pressure on $\mathrm{F}$ - and, consequently, union-wide inflation, $\mathrm{H}$ will react even by less than under [HF]M. $\mathrm{H}$ government spending is thus raised by less than under $[\mathrm{HF}] \mathrm{M}$, resulting in negative average inflation, and the Central Bank lowers interest rate. H-taxes, however, rise by even more, moving closer to the efficient level.

As a result, HFM yields much less volatile inflation at Home, and only slightly more volatile

\footnotetext{
${ }^{24}$ Auray and Eyquem (2014) showed that incomplete markets (autarky) may produce lower welfare costs than complete markets.

${ }^{25}$ The numbers are given in Panel C, Table 1.
} 
Panel I: Cooperative regime vs. Regime of simultaneous fiscal moves
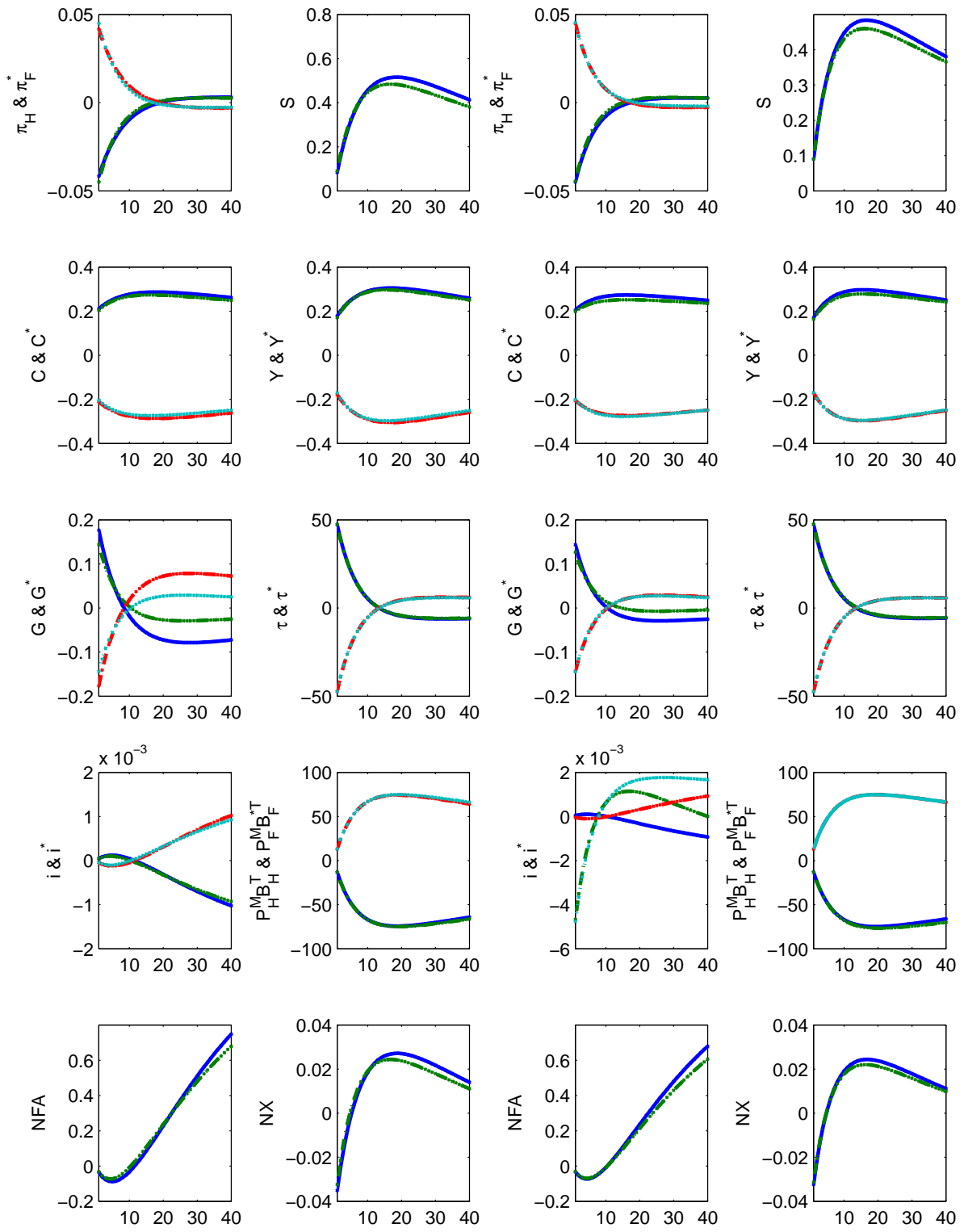

$\longrightarrow H_{C}, \cdots, H_{[H F] M}=--F_{C}, \ldots, F_{[H F] M}$

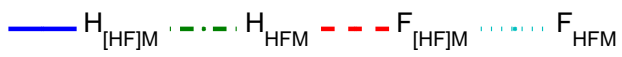

Figure 4: Impulse responses to an asymmetric cost-push shock of size 1, negative in country $\mathrm{H}$ and positive in country F. Countries are identical, with $\varrho=0$ and $\omega=1$. 
inflation in country F. Volatility of the terms of trade falls, which helps to stabilize demand in both countries. The leader gains more not only relative to [HF]M but also relative to cooperation, as there is a substantial reduction in overall volatility. The reduction in interest rate does not allow the follower's consumption to reduce too much, so there is welfare stabilization gains even for the follower, and for the monetary policymaker relative to [HF]M.

The resulting ranking of non-cooperative regimes is given in Panel $\mathrm{C}$ (right), Table 1 . As the follower $\mathrm{F}$ also gains in equilibrium $\left(L_{N}, F_{N}\right)$, there is no incentive to fight over the leadership, and there are two Nash equilibria with sequential moves of policymakers, $\left(L_{N}, F_{N}\right)$ and $\left(F_{N}, L_{N}\right)$, see Table 2, Panel A2.

These two Nash equilibria do not survive in the extended four-by-four game, where each fiscal policymaker can also decide on whether to adopt the union-wide objective. Equilibrium $\left(F_{N}, L_{N}\right)$ is dominated by unilateral adoption of the union-wide objective by country $\mathrm{H}$, equilibrium $\left(F_{U}, L_{N}\right)$ is Pareto-preferred to $\left(F_{N}, L_{N}\right)$ and is a new Nash equilibrium.

When the follower adopts the union-wide objective function, it now attaches some weight to the objectives of the leading country. The leader anticipates this and, since cross-border effects of the fiscal policy of the follower are large, it will now react much less than if the follower is nationally-oriented. On the one hand, this will improve the stabilization of the follower and, on the other hand, it will also improve the stabilization of the leader through a stronger interest rate reaction. Both countries achieve better stabilization in $\left(F_{U}, L_{N}\right)$ compared to $\left(F_{N}, L_{N}\right)$. Similarly, $\left(L_{N}, F_{U}\right)$ dominates $\left(L_{N}, F_{N}\right)$, see Table 2, Panel B2.

Apart from the two asymmetric equilibria $\left(L_{N}, F_{U}\right)$ and $\left(F_{U}, L_{N}\right)$, there is a Nash equilibrium which replicates the cooperative outcome as all authorities adopt the same union-wide objectives, $\left(L_{U}, L_{U}\right)$. If a policymaker cannot convey itself as an intra-period leader, the cooperative outcome will realize in which both fiscal policymakers move simultaneously, and use union-wide objectives. As discussed above, equilibrium $\left(L_{U}, L_{U}\right)$ produces lower welfare stabilization costs than the equilibrium where both fiscal policymakers adopt national objectives, $\left(L_{N}, F_{N}\right)$. Unilateral deviation $\left(L_{N}, L_{U}\right)$ from $\left(L_{U}, L_{U}\right)$ is not beneficial: fiscal policy responses are no longer symmetric, monetary policy is non-neutral and ends up by improving the stabilization of the country with union-wide objectives. 
Table 3: Regime of Simultaneous Moves, Fiscal choice of national and union-wide objective

\begin{tabular}{lc|cc|cc} 
& \multicolumn{3}{c|}{\begin{tabular}{c} 
Technology shocks, $\% \mathrm{C} \times 10^{2}$ \\
\multicolumn{2}{c}{ Cost-push shocks, $\% \mathrm{C} \times 10^{2}$} \\
\end{tabular}} & & \multicolumn{2}{c}{ Foreign Country } & \multicolumn{2}{c}{ Foreign Country } \\
Home & $N$ & $(0.553,0.553)$ & $(0.586,0.510)$ & $(1.007,1.007)$ & $(0.995,0.884)$ \\
Country & $U$ & $(0.510,0.586)$ & $\mathbf{( 0 . 5 3 8 , 0 . 5 3 8 )}$ & $(0.884,0.995)$ & $\mathbf{( 0 . 9 3 7 , 0 . 9 3 7 )}$
\end{tabular}

\section{Extensions}

\subsection{Regime of Simultaneous Moves}

Suppose all three policymakers move simultaneously, unable to take into account each other policy reaction function. This regime of simultaneous moves leads to relatively high welfare losses, compared to the cooperative regime and to the regime with fiscal leadership [HF]M. ${ }^{26}$

Table 3 reports outcomes in two-by-two games in which the fiscal policymaker, being unable to choose the date of the Fiscal Policy Committee meeting and to exploit other policymakers' reaction functions, is still able to decide on whether unilaterally adopt the union-wide policy objective (strategy $U$ ) or retain the national objective (strategy $N$ ). Equilibrium $(N, N)$, therefore, describes the regime of simultaneous moves of all policymakers, while equilibrium $(U, U)$ describes cooperation. This table suggests that cooperation is sustainable under both types of shock.

However, our previous results suggest that any optimizing fiscal policymaker who has an ability to use information about the monetary policy will be better off using it, and the cooperative equilibrium is not sustainable in an environment with these additional strategies.

\subsection{Heterogeneous Monetary Union}

The analysis in Section 4 uses symmetric monetary union model with zero steady state holdings of foreign debt, $\varrho=0$. We now investigate how the results change in an asymmetric monetary union, calibrated to the actual data for Core and Periphery EMU country blocks, see Section 2.3.

Table 4 presents the results for the country-size asymmetric monetary union. The qualitative results are similar to those reported in Table 2 for the symmetric monetary union: cooperation is not a sustainable Nash equilibrium under technology shocks, and there is multiplicity of Nash equilibria under cost push shocks, although the best sustainable equilibrium is now $\left(F_{N}, L_{N}\right)$ instead of $\left(F_{U}, L_{N}\right)$ for symmetric countries. There are also some quantitative differences. The

\footnotetext{
${ }^{26}$ This is consistent with findings in the literature, see e.g. Dixit and Lambertini (2003).
} 
Table 4: Policy coordination in country size asymmetric monetary union Panel $A$ : Choice of leadership, $\% \mathrm{C} \times 10^{2}$

A1: Technology shocks

Large Foreign Country
A2: Cost-push shocks

Large Foreign Country

\begin{tabular}{lc|cc|cc} 
& & $L_{N}$ & $F_{N}$ & $L_{N}$ & $F_{N}$ \\
\cline { 2 - 6 } Small Home & $L_{N}$ & $\mathbf{( 0 . 7 3 0 , 0 . 4 4 4 )}$ & $(0.729,0.447)$ & $(1.051,0.945)$ & $\mathbf{( 1 . 0 3 7 , 0 . 9 4 4 )}$ \\
\multirow{2}{*}{ Country } & & & & & {$[0.971]$} \\
& $F_{N}$ & $(0.749,0.443)$ & $(0.730,0.444)$ & $\left(\begin{array}{c}\mathbf{1 . 0 4 7 , 0 . 8 9 9}) \\
{[0.941]}\end{array}\right.$ & $(1.051,0.945)$
\end{tabular}

Panel $B$ : Choice of leadership and the type of objective, $\% \mathrm{C} \times 10^{2}$

B1: Technology shocks

Large Foreign Country

\begin{tabular}{lc|cccc} 
& & $L_{N}$ & $L_{U}$ & $F_{N}$ & $F_{U}$ \\
\cline { 2 - 6 } Small & $L_{N}$ & $(\mathbf{0 . 7 3 0 , 0 . 4 4 4})$ & $(0.667,0.459)$ & $(0.729,0.447)$ & $(0.658,0.474)$ \\
Home & $L_{U}$ & $(0.740,0.438)$ & $(0.680,0.452)$ & $(0.735,0.440)$ & $(0.680,0.452)$ \\
Country & $F_{N}$ & $(0.749,0.443)$ & $(0.676,0.455)$ & $(0.730,0.444)$ & $(0.667,0.459)$ \\
& $F_{U}$ & $(0.759,0.438)$ & $(0.680,0.452)$ & $(0.740,0.438)$ & $(0.680,0.452)$
\end{tabular}

B2: Cost-push shocks

Large Foreign Country

\begin{tabular}{|c|c|c|c|c|c|}
\hline & & $L_{N}$ & $L_{U}$ & $F_{N}$ & $F_{U}$ \\
\hline Small & $L_{N}$ & $(1.051,0.945)$ & $(1.049,0.933)$ & $(1.037,0.944)$ & $\begin{array}{c}\mathbf{( 1 . 0 0 6 , 0 . 9 3 1 )} \\
{[0.952]}\end{array}$ \\
\hline Home & $L_{U}$ & $(1.051,0.946)$ & $\begin{array}{c}(\mathbf{1 . 0 3 3}, \mathbf{0 . 9 1 5}) \\
{[0.949]}\end{array}$ & $(1.034,0.946)$ & $(1.033,0.915)$ \\
\hline Country & $F_{N}$ & $\begin{array}{c}(\mathbf{1 . 0 4 7 , 0 . 8 9 9}) \\
{[0.941]}\end{array}$ & $(1.048,0.901)$ & $(1.051,0.945)$ & $(1.049,0.933)$ \\
\hline & $F_{U}$ & $(1.054,0.897)$ & $(1.033,0.915)$ & $(1.051,0.946)$ & $(1.033,0.915)$ \\
\hline
\end{tabular}

level of losses depends on parameterization, in particular on the degree of country-size asymmetry, on the level of debt, external exposure and imbalances.

In a country-size asymmetric monetary union, the smaller country suffers more from the consequences of an asymmetric shock, because the change in the terms of trade has a bigger effect on the marginal cost and therefore on its inflation rate. In addition, asymmetric shocks result in union-wide effects, to which the Central Bank reacts, effectively stabilizing the larger country's economy. Because of these two reasons, the smaller country's fiscal policy has to intervene more, which usually results in greater volatility of fiscal instruments and higher stabilization costs. Therefore, the first number in matrix-entries in Table 4 is always greater than the second number.

The scaling of losses does not change the individual ranking of policy regimes, but the country- 
size effects are more than simple scaling. A change in the relative country size affects the relative ability of policymakers to exploit reaction functions of each other and of the monetary policymaker, which may result in different Nash equilibria in an asymmetric monetary union.

In case of technology shocks the country-size effects on the equilibrium outcome in Table 4 are limited. The outcome is determined by the individual ranking of outcomes in non-cooperative regimes [HF]M, HFM and FHM. Regardless of country size, the leader gains and the follower loses in the sequential regimes HFM and FHM relative to their payoffs in [HF]M.

If there are no steady state non-resident holdings of debt, $\varrho=0$, then under cost push shocks the country-size effects result in only two Nash equilibria in the extended four-by-four game, $\left(L_{U}, L_{U}\right)$ and $\left(L_{N}, F_{U}\right)$. Greater non-resident holdings of debt $(\varrho>0)$ but equal steady-state external debts $(\omega=1)$ does not affect the ranking of regimes. ${ }^{27}$

However, making Home country net external debtor with $\varrho>0$ and $\omega<1$ results in additional asymmetries and results in (re-)appearence of the third equilibrium $\left(F_{N}, L_{N}\right)$ under cost-push shocks. In this case the net external debtor has to generate current account surplus to pay for the debt service. The small Home country becomes even 'smaller' with lower steady state consumption and spending. As a net debtor under cost-push shocks, the small $\mathrm{H}$ country has now less incentives to adopt the union-wide objectives. Indeed, as cross-border effects of its policy are small, and the $\mathrm{H}$ country attaches a large relative weight to the objectives of the large $\mathrm{F}$ country under union-wide metrics, $\mathrm{H}$ reacts much less than it does under national objectives, and optimal actions of the larger country have destabilizing effects on $\mathrm{H}$. These asymmetries become sufficiently large and the small-size country $\mathrm{H}$ sees the reduction of losses if it keeps the national objective, therefore outcome $\left(F_{N}, L_{N}\right)$ emerges as a Nash equilibrium.

Finally, a unilateral increase of steady state debt to output ratio in small country $\mathrm{H}$ yields it higher stabilization losses for both types of shocks, while large country F gains under technology shocks and loses under cost push shocks. However, the relative change is numerically small, without implications for the ranking of regimes and for stability of policy equilibria.

\subsection{Coordinating Role of a Central Bank}

In this section we illustrate one way the Central Bank can affect the equilibrium outcome if an additional monetary instrument is provided. This is an extreme simplification of ideas presented in Corsetti et al. $(2017){ }^{28}$

\footnotetext{
${ }^{27}$ Additional figures and tables are given in Appendix E.

${ }^{28}$ The section was added following Discussant's suggestions. We leave the detailed analysis of this policy proposal for future research as it deserves much more thoughts and deeper investigation than a section in this paper might
} 
Table 5: Policy coordination under cost-push shocks, Central Bank has two instruments Panel $A$ : Fiscal choice of leadership, $\% \mathrm{C} \times 10^{3}$

\begin{tabular}{lc|cc} 
& \multicolumn{2}{c}{ Foreign Country } \\
& & $L_{N}$ & $F_{N}$ \\
\cline { 2 - 4 } Home & $L_{N}$ & $(0.11662,0.11662)$ & $\mathbf{( 0 . 1 1 3 7 0 , 0 . 1 1 6 6 0 )}$ \\
Country & $F_{N}$ & $\mathbf{( 0 . 1 1 6 6 0 , 0 . 1 1 3 7 0 )}$ & $(0.11662,0.11662)$
\end{tabular}

Panel $B$ : Fiscal choice of leadership and the type of objective, $\% \mathrm{C} \times 10^{3}$

\begin{tabular}{ll|cccc}
\multicolumn{1}{c}{} & & \multicolumn{4}{c}{ Foreign Country } \\
& & $L_{N}$ & $L_{U}$ & $F_{N}$ & $F_{U}$ \\
\cline { 2 - 6 } Home & $L_{N}$ & $(0.11662,0.11662)$ & $(0.11638,0.11621)$ & $(0.11370,0.11660)$ & $(0.11247,0.11622)$ \\
Country & $L_{U}$ & $(0.11621,0.11638)$ & $\mathbf{( 0 . 1 1 4 9 7 , 0 . 1 1 4 9 7 )}$ & $(0.11416,0.11650)$ & $(0.11497,0.11497)$ \\
& $F_{N}$ & $(0.11660,0.11370)$ & $(0.11650,0.11416)$ & $(0.11662,0.11662)$ & $(0.11638,0.11621)$ \\
& $F_{U}$ & $(0.11622,0.11247)$ & $(0.11497,0.11497)$ & $(0.11621,0.11638)$ & $(0.11497,0.11497)$
\end{tabular}

Suppose that in the setup of our model, the Central Bank can buy government bonds using a fund, backed by lump sum taxes. The two linearized government budget constraints, equations (5) and (10) become

$$
\begin{aligned}
& \hat{d}_{H t}+\frac{Y^{*}}{Y} \hat{d}_{H t}^{*}=4 \frac{\delta_{H}}{\beta} \hat{R}_{t}+\frac{1}{\beta} \hat{d}_{H t-1}+\frac{1}{\beta} \frac{Y^{*}}{Y} \hat{d}_{H t-1}^{*}+\frac{G}{Y} \hat{G}_{t} \\
& -\frac{\tau^{l}}{\mu}\left(\gamma \hat{S}_{t}+(\varsigma+1)\left(\hat{Y}_{t}-\hat{Z}_{t}\right)+\frac{1}{\sigma} \hat{C}_{t}+\left(1+\frac{\tau^{l}}{\mu}\right) \hat{\tau}_{t}^{l}\right)+\hat{L}_{t}, \\
& \frac{Y}{Y^{*}} \hat{d}_{F t}+\hat{d}_{F t}^{*}=4 \frac{\delta_{F}}{\beta} \hat{R}_{t}^{*}+\frac{1}{\beta} \frac{Y}{Y^{*}} \hat{d}_{F t-1}+\frac{1}{\beta} \hat{d}_{F t-1}^{*}+\frac{G^{*}}{Y^{*}} \hat{G}_{t}^{*} \\
& -\frac{\tau^{l *}}{\mu}\left(-\gamma^{*} \hat{S}_{t}+(\varsigma+1)\left(\hat{Y}_{t}^{*}-\hat{Z}_{t}^{*}\right)+\frac{1}{\sigma} \hat{C}_{t}^{*}+\left(1+\frac{\tau^{* l}}{\mu}\right) \hat{\tau}_{t}^{* l}\right)-\frac{Y}{Y^{*}} \hat{L}_{t} .
\end{aligned}
$$

Here $\hat{L}_{t}$ is the (normalized) net borrowing of country $\mathrm{H}$ from the fund. Because of the zero union-wide net supply of funds, country F's net lending - channeled via the fund - is $\frac{Y}{Y^{*}} \hat{L}_{t}$. We assume that the Central Bank can use $\hat{L}_{t}$ as an additional (asymmetric) policy instrument.

This instrument has a potential to completely offset effects of cost push shocks. As discussed in Section 4, taxes do not offset cost-push shocks only because of debt sustainability issues. Once the new instrument, which can ensure debt sustainability in case of asymmetric shocks, is provided, complete stabilization can be achieved. We do not impose any realistic constraints on the use of $\hat{L}_{t}$ and keep the same leadership assumption: the Central Bank is a follower in monetary-fiscal policy interactions, but now has two policy instruments instead of one. ${ }^{29}$ The allow.

${ }^{29}$ Realistic treatment would require to impose budget constraints on each country's borrowing from the fund, 
results for cost-push shocks are presented in Table 5 , which can be compared to Table $2 .{ }^{30}$

As anticipated, the level of overall losses reduce substantially. However, the ranking of policy regimes also changes. Policymakers will choose union-wide objective unilaterally and coordinate on the unique cooperative equilibrium $\left(L_{U}, L_{U}\right)$, which is the best for the Central Bank.

The new instrument does not affect qualitative results in case of technology shocks, although the level of losses falls. ${ }^{31}$ Complete stabilization is impossible, and fiscal policymakers still face Prisoner's dilemma and do not coordinate on the Pareto-preferred cooperative equilibrium.

\section{Conclusion}

This paper studies monetary and fiscal policy coordination in a monetary union. We demonstrate that cooperation of fiscal policymakers is unlikely to be sustainable as a Nash equilibrium. The outcome is however shock-dependent. Under efficient technology shocks the fiscal authorities have in a Prisoner dilemma-type coordination problem and the socially and individually preferred cooperative outcome is not a Nash equilibrium. Under inefficient cost push shocks, multiple Nash equilibria arise. The cooperative outcome can be achieved in one of these equilibria but it is not the union-wide-preferred. We argue that the pervasive multiplicity of policy equilibria and coordination failures suggest an important coordinating role for a supranational authority. This role can be naturally taken by the Central Bank, as it has access to the same information as the fiscal authorities and can easily communicate with them.

Of course, the latter conclusion is tailored to our normative analysis: with perfect and complete information about each agent's information set and the set of strategies. However, even in our setup, this paper does not design policy coordination mechanism, either for the Central Bank or for any other coordinator, apart from illustrating how an additional policy instrument of a Central Bank might work. We had more modest aim to investigate sustainability of policy equilibria, demonstrate the existence of coordination failures and the need for a coordinator. Our model, therefore, abstracts from many features that a realistic economy has; in particular, national fiscal authorities' policy objectives may be more realistically described as having penalties on large movements of fiscal instruments thus reflecting restricted fiscal space. However, once the nature of policy interactions and coordination failures are well understood, we will be better equipped to solve a range of practical problems.

set some criteriafor access to the fund. We therefore also ignore any reduction in risk premium which may be associated with borrowing from such fund.

${ }^{30}$ We impose small penalty on movements of $\hat{L}_{t}$ to prevent complete stabilization.

${ }^{31}$ Results are given in Appendix G. 


\section{References}

Adolfson, M., S. Laseen, J. Linde, and L. E. Svensson (2011). Optimal Monetary Policy in an Operational Medium-Sized DSGE Model. Journal of Money, Credit and Banking, 43 (7), 12871331.

Adolfson, M., S. Laseen, J. Linde, and M. Villani (2008). Empirical properties of Closed- and Open-economy DSGE Models of the Euro Area. Macroeconomic Dynamics, 12 (s1), 2-19.

Albonico, A., A. Paccagnini, and P. Tirelli (2016). PIIGS in the Euro Area. An Empirical DSGE Model. Working Papers 331, University of Milano-Bicocca.

Attanasio, O. P. and G. Weber (1995). Is Consumption Growth Consistent with Intertemporal Optimization? Evidence from the Consumer Expenditure Survey. Journal of Political Economy, 103 (6), 1121-1157.

Aumann, R. J. (1974). Subjectivity and Correlation in Randomized Strategies. Journal of Mathematical Economics, 1, 67-96.

Aumann, R. J. (1987). Correlated Equilibrium as and Expression of Bayesian Rationality. Econometrica, 55 (1), 1-18.

Auray, S. and A. Eyquem (2014). Welfare Reversals in a Monetary Union. American Economic Journal: Macroeconomics, 6 (4), 246-290.

Bache, I., L. Brubakk, and J. Maith (2010). Simple Rules Versus Optimal Policy: What Fits? Norges Bank Working Paper No. 2010/03, Available at SSRN: http://ssrn.com/abstract $=1612284$.

Backus, D. and J. Driffill (1986). The Consistency of Optimal Policy in Stochastic Rational Expectations Models. CEPR Discussion Paper 124, London.

Baele, L., A. Ferrando, P. Hördahl, E. Krylova, and C. Monnet (2004). Measuring European Financial Integration. Oxford Review of Economic Policy, 20 (4), 509-530.

Bargain, O., M. Dolls, C. Fuest, D. Neumann, A. Peichl, N. Pestel, and S. Siegloch (2013). Fiscal union in Europe? Redistributive and stabilizing effects of a European tax-benefit system and fiscal equalization mechanism. Economic Policy, 28 (75), 375-422. 
Beetsma, R. and X. Debrun (2004). The interaction between monetary and fiscal policies in a monetary union: a review of recent literature. In Fiscal Policies, Monetary Policies and Labour Markets. Key Aspects of European Macroeconomic Policymaking after Monetary Unification. Cambridge University Press.

Beetsma, R. and M. Giuliodori (2010). The Macroeconomic Costs and Benefits of the EMU and Other Monetary Unions: An Overview of Recent Research. Journal of Economic Literature, 48 (3), 603-641.

Benigno, P. (2009). Price Stability with Imperfect Financial Integration. Journal of Money, Credit and Banking, 41 (s1), 121-149.

Benigno, P. and G. Benigno (2003). Price Stability in Open Economies. Review of Economic Studies, 70 (4), 743-764.

Bergo, J. (2007). Interest rate projections in theory and practice. Speech by Deputy Governor Jarle Bergo at the Foreign Exchange Seminar of the Association of Norwegian Economists at Sanderstolen.

Bernanke, B. S. and F. S. Mishkin (1997). Inflation targeting: A new framework for monetary policy? Journal of Economic Perspectives, 11 (2), 97 -116.

Bianchi, F. (2013). Regime Switches, Agents' Beliefs, and Post-World War II U.S. Macroeconomic Dynamics. Review of Economic Studies, 80 (2), 491-511.

Blake, A. P. and T. Kirsanova (2011). Inflation-Conservatism and Monetary-Fiscal Policy Interactions. International Journal of Central Banking, 7 (2), 41-83.

Calvo, G. (1983). Staggered Prices in a Utility-Maximising Framework. Journal of Monetary Economics, 12, 383-398.

Chari, V. and P. J. Kehoe (2007). On the need for fiscal constraints in a monetary union. Journal of Monetary Economics, 54 (8), 2399-2408.

Chen, X., T. Kirsanova, and C. Leith (2017a). An Empirical Assessment of Optimal Monetary Policy Delegation in the Euro Area. European Economic Review, 100, 95-115.

Chen, X., T. Kirsanova, and C. Leith (2017b). How Optimal is US Monetary Policy? Journal of Monetary Economics. In Press. doi: 10.1016/j.jmoneco.2017.09.009. 
Chen, X., E. M. Leeper, and C. Leith (2015). US Monetary and Fiscal Policies - Conflict or Cooperation? SIRE Discussion Paper 77, http://repo.sire.ac.uk/handle/10943/685.

Clarida, R. H., J. Galí, and M. Gertler (1999). The Science of Monetary Policy: A New Keynesian Perspective. Journal of Economic Literature, 37, 1661-1707.

Coroneo, L., V. Corradi, and P. Santos Monteiro (2013). Testing for optimal monetary policy via moment inequalities. The University of York Discussion Paper 13/07.

Corsetti, G., M. Higgins, and P. Pesenti (2017). Policies and Institutions for Managing the Aggregate Macroeconomic Stance of the Eurozone. VoxEU, February 12.

Currie, D. and P. Levine (1993). Rules, Reputation and Macroeconomic Policy Coordination. Cambridge: Cambridge University Press.

Debortoli, D. and A. Lakdawala (2016). How Credible is the Federal Reserve? A Structural Estimation of Policy Re-optimizations. American Economic Journal: Macroeconomics, 8 (3), $42-76$.

Dixit, A. and L. Lambertini (2003). Symbiosis of Monetary and Fiscal Policies in a Monetary Union. Journal of International Economics, 60 (2), 235-247

Ferrero, A. (2009). Fiscal and monetary rules for a currency union. Journal of International Economics, 77, 1-10.

Fragetta, M. and T. Kirsanova (2010). Strategic Monetary and Fiscal Policy Interactions: An Empirical Investigation. European Economic Review, 54 (7), 855-879.

Givens, G. E. (2012). Estimating Central Bank Preferences under Commitment and Discretion. Journal of Money, Credit and Banking, 44 (6), 1033-1061.

Justiniano, A. and B. Preston (2010). Monetary policy and uncertainty in an empirical small open-economy model. Journal of Applied Econometrics, 25 (1), 93-128.

King, M. (1997). Changes in UK Monetary Policy: Rules and Discretion in Practice. Journal of Monetary Economics, 39, 81-97.

Kirsanova, T., M. Satchi, D. Vines, and S. Wren-Lewis (2007). Optimal Fiscal Policy Rules in a Monetary Union. Journal of Money, Credit and Banking, 39 (7), 1759-1784. 
Le Roux, S. and T. Kirsanova (2013). Commitment vs. Discretion in the UK: An Empirical Investigation of the Monetary and Fiscal Policy Regime. International Journal of Central Banking, 9 (4), 99-151.

Leeper, E. M. and C. Leith (2016). Understanding Inflation as a Joint Monetary-Fiscal Phenomenon. In H. Uhlig and J. Taylor (Eds.), Handbook of Macroeconomics, Volume 2, pp. 2305-2415. Elsevier.

Leith, C. and S. Wren-Lewis (2011). Discretionary policy in a monetary union with sovereign debt. European Economic Review, 55, 93-117.

Liu, P. and H. Mumtaz (2011). Evolving Macroeconomic Dynamics in a Small Open Economy: An Estimated Markov Switching DSGE Model for the UK. Journal of Money, Credit and Banking, 43 (7), 1443-1474.

Lubik, T. and F. Schorfheide (2005). A Bayesian Look at the New Open Economy Macroeconomics. In NBER Macroeconomics Annual 2005, pp. 313-379.

Oudiz, G. and J. Sachs (1985). International policy coordination in dynamic macroeconomic models. In W. H. Buiter and R. C. Marston (Eds.), International Economic Policy Coordination. Cambridge: Cambridge University Press.

Smets, F. and R. Wouters (2003). An Estimated Dynamic Stochastic General Equilibrium Model of the Euro Area. Journal of the European Economic Association, 1 (1), 1123-75.

Söderlind, P. (1999). Solution and Estimation of RE Macromodels with Optimal Policy. European Economic Review, 43, 813-823.

Svensson, L. E. (2009). Transparency under flexible inflation targeting: Experiences and challenges. Sveriges Riksbank Economic Review, 1, 5-44.

Svensson, L. E. O. (2003). What Is Wrong with Taylor Rules? Using Judgment in Monetary Policy through Targeting Rules. Journal of Economic Literature, 41 (2), 426-477.

Woodford, M. (2001). Fiscal Requirements for Price Stability. Journal of Money, Credit and Banking, 33, 669-728.

Woodford, M. (2003). Interest and Prices: Foundations of a Theory of Monetary Policy. Princeton, NJ.: Princeton University Press. 